\title{
Calcium/Calmodulin-Dependent Protein Kinase II in Cerebrovascular Diseases
}

\author{
Xuejing Zhang ${ }^{1} \cdot$ Jaclyn Connelly ${ }^{1} \cdot$ Edwin S. Levitan ${ }^{1} \cdot$ Dandan Sun $^{2} \cdot$ Jane Q. Wang $^{1}$ (C)
}

Received: 12 August 2020 / Revised: 20 November 2020 / Accepted: 17 February 2021 / Published online: 13 March 2021

(C) The Author(s) 2021

\begin{abstract}
Cerebrovascular disease is the most common life-threatening and debilitating condition that often leads to stroke. The multifunctional calcium/calmodulin-dependent protein kinase II (CaMKII) is a key $\mathrm{Ca}^{2+}$ sensor and an important signaling protein in a variety of biological systems within the brain, heart, and vasculature. In the brain, past stroke-related studies have been mainly focused on the role of CaMKII in ischemic stroke in neurons and established CaMKII as a major mediator of neuronal cell death induced by glutamate excitotoxicity and oxidative stress following ischemic stroke. However, with growing understanding of the importance of neurovascular interactions in cerebrovascular diseases, there are clearly gaps in our understanding of how CaMKII functions in the complex neurovascular biological processes and its contributions to cerebrovascular diseases. Additionally, emerging evidence demonstrates novel regulatory mechanisms of CaMKII and potential roles of the less-studied CaMKII isoforms in the ischemic brain, which has sparked renewed interests in this dynamic kinase family. This review discusses past findings and emerging evidence on CaMKII in several major cerebrovascular dysfunctions including ischemic stroke, hemorrhagic stroke, and vascular dementia, focusing on the unique roles played by CaMKII in the underlying biological processes of neuronal cell death, neuroinflammation, and endothelial barrier dysfunction triggered by stroke. We also highlight exciting new findings, promising therapeutic agents, and future perspectives for CaMKII in cerebrovascular systems.
\end{abstract}

Keywords Cerebrovascular disease $\cdot$ CaMKII $\cdot$ Stroke $\cdot$ Vascular dementia $\cdot$ Neuronal cell death $\cdot$ Neuroinflammation Endothelial barrier dysfunction

\section{Introduction}

Cerebrovascular disease affects blood vessels and cerebral circulation of the brain and is a common cause of death and disability worldwide. Stoke, either ischemic or hemorrhagic, is a major form of cerebrovascular disease. In the USA, stroke reduces mobility in more than half of stroke survivors age 65 and over, and

Dandan Sun

sund@upmc.edu

Jane Q. Wang

qjw1@pitt.edu

1 Department of Pharmacology and Chemical Biology, University of Pittsburgh School of Medicine, E1354 BST, Pittsburgh, PA, USA

2 Department of Neurology, Pittsburgh Institute For

Neurodegenerative Diseases, University of Pittsburgh, 7016

Biomedical Science Tower-3, 3501 Fifth Ave.,

Pittsburgh, PA 15260, USA approximately $3 \%$ of males and $2 \%$ of females reported that they were disabled because of stroke [1]. Subarachnoid hemorrhage (SAH), a less common type of hemorrhagic stroke, accounts for $5 \%$ of stroke cases in the USA [2]. Severe reduction of cerebral blood flow also leads to a complex neurodegenerative disorder known as vascular dementia which associates with memory and cognitive impairment. Stroke as a major form of cerebrovascular disease has been intensely studied with the primary focus on neuronal injury, the main functional deficit of the disease. However, there is growing appreciation in the functional interactions within the multicellular neurovascular unit and their crucial roles in the onset, progression, and recovery after ischemic stroke $[3,4]$.

CaMKII is a family of calcium $\left(\mathrm{Ca}^{2+}\right)$ and calmodulin $(\mathrm{CaM})$-activated multifunctional serine/threonine kinases [5]. It was first discovered in the brain and subsequently shown to play a critical role in brain function, particularly in memory and learning [6]. In ischemic stroke, CaMKII was found to be activated in the early phase of ischemic insult 
and mediates glutamate excitotoxicity-induced cell death in neurons. However, downstream events leading to cell death remain obscure. Additionally, past studies mainly focus on CaMKII holoenzyme and $\mathrm{CaMKII} \alpha$ (the most abundant CaMKII isoform in the brain) in neurons, but there is sparse information on CaMKII in other cell types within the neurovascular unit (such as endothelial cells, pericytes, smooth muscle cells, astrocytes, microglia, and extracellular matrix) and the functions of other CaMKII isoforms in ischemic stroke are largely unknown. In this review, by revisiting several key biological processes triggered by ischemic or hemorrhagic brain injury, we seek to discuss the diverse functions and signaling mechanisms of CaMKII in cerebrovascular disease in the context of the multicellular neurovascular environment.

\section{Structure and Regulation of CaMKII}

\section{Basic Enzyme Structure and Classification}

CaMKII is a family of serine/threonine kinases activated by $\mathrm{Ca}^{2+}$ and CaM. Four isoforms $(\alpha, \beta, \gamma$, and $\delta)$ have been identified. Each CaMKII holoenzyme typically comprises 12 or 14 subunits of the same or different isoforms [7-11]. The homo- or heteromeric structures confer unique properties to CaMKII based on which isoforms and/or subtypes are present [8]. As shown in Fig. 1, the conserved basic structure of CaMKII includes a N-terminal catalytic domain that contains the ATP binding site, a regulatory domain that encompasses an autoinhibitory region, multiple conserved phosphorylation sites, and $\mathrm{Ca}^{2+} / \mathrm{CaM}$ binding site required for activation, and a C-terminal association domain that includes a variable region and an association motif that is essential for oligomerization [7-10, 12]. CaMKII is a key regulator of neuronal function and has been studied extensively in areas of learning, synaptic plasticity, and memory [6, 7].

The four isoforms of CaMKII all have conserved domain structures but are derived from different genes [7]. It is a common occurrence for tissues to express more than one isoform of CaMKII [10]. The variable region provides the main structural distinctions between isoforms. Further diversification occurs as a result of alternative splicing in the variable region to produce around 40 different subtypes for the four isoforms [12-14].

All four CaMKII isoforms reside in the brain, though $\mathrm{CaMKII} \alpha$ and $\mathrm{CaMKII} \beta$ are known to be more prevalent there, while $\mathrm{CaMKII} \delta$ is more abundant in the cardiovascular system and CaMKII $\gamma$ is ubiquitously expressed [8-10]. In particular, $\mathrm{CaMKII} \alpha$ is most prevalent in neurons and accounts for more than $1 \%$ of protein in some areas of the brain such as the hippocampus and postnatal forebrain neurons [7, 9].

\section{Mechanisms of Activation}

In the absence of stimuli, each subunit of CaMKII is kept in a basal/inactive state by the interactions between its catalytic domain and the autoinhibitory region within the regulatory domain [9]. The alpha helical structure of the autoinhibitory region contains two sequences that overlap with each other, an

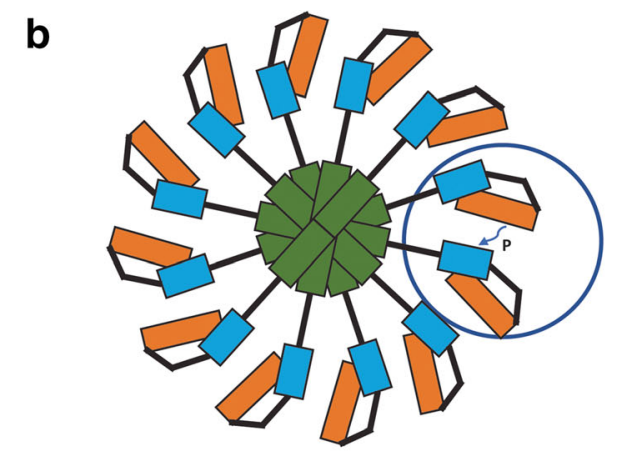

C
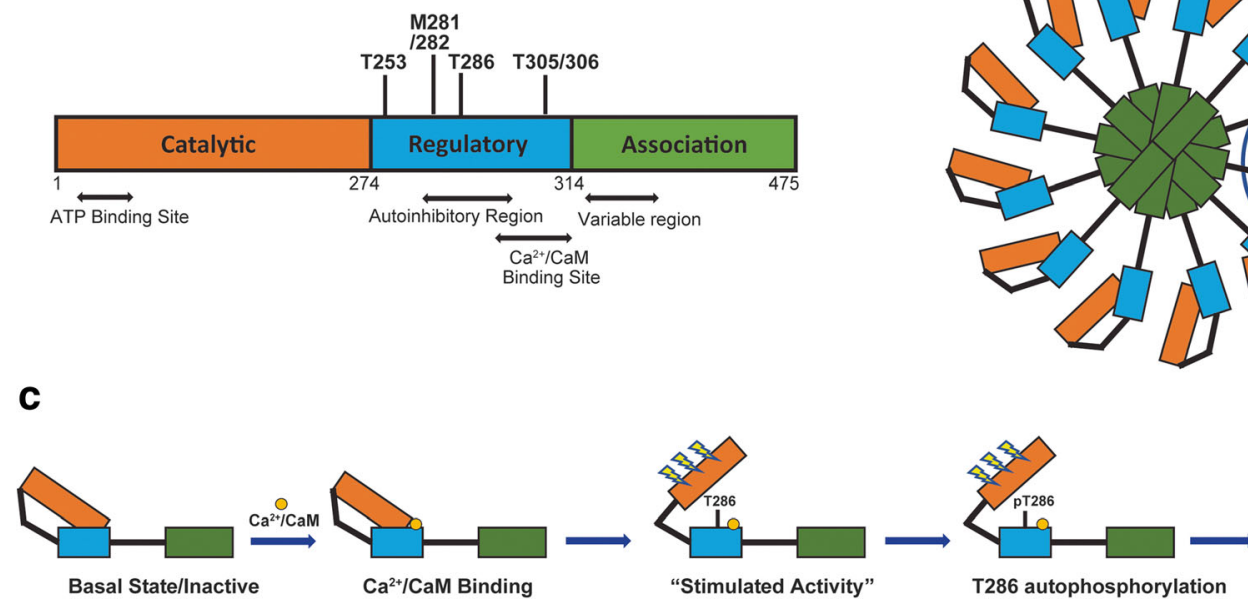

T286 autophosphorylation

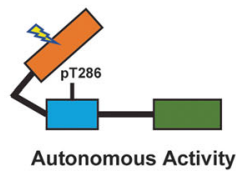

Fig. 1 Diagram of CaMKII structure and mechanisms of activation. a The sequence of CaMKII includes a N-terminal catalytic domain that contains the ATP binding and substrate phosphorylation sites, a regulatory domain that contains the autoinhibitory region, the $\mathrm{Ca}^{2+} / \mathrm{CaM}$ binding site, and multiple post-translational modification sites including phosphorylation sites T253, T286, and T305/306 and the M281/282 oxidation

sites, and a C-terminal association domain that mediates multimeric interactions and a variable region that can undergo alternative splicing to generate a variety of CaMKII subtypes. b Schematic depiction of CaMKII holoenzyme with 12 subunits. c Activation mechanism of a CaMKII monomer by the binding of $\mathrm{Ca}^{2+} / \mathrm{CaM}$ and autophosphorylation at T286 
auto-inhibition sequence and a CaM binding sequence [7, 9]. The conserved threonine 286 (T286) (T287 for CaMKII $\beta, \delta$, $\gamma)$ phosphorylation site resides in the autoinhibition sequence, and two other conserved phosphorylation sites, T305/306, reside in the $\mathrm{Ca}^{2+} / \mathrm{CaM}$ binding sequence in the regulatory domain (Fig. 1a) [7-9, 12]. The T286 amino acid binds to a conserved site in the catalytic domain to maintain the inactive conformation.

The activation of the CaMKII is triggered by an increase in intracellular $\mathrm{Ca}^{2+}$ levels and the binding of $\mathrm{Ca}^{2+}$ to $\mathrm{CaM}$ to form the $\mathrm{Ca}^{2+} / \mathrm{CaM}$ complex. $\mathrm{Ca}^{2+} / \mathrm{CaM}$ then binds to the $\mathrm{Ca}^{2+} / \mathrm{CaM}$ binding site in the regulatory domain to induce a conformational change that allows the catalytic domain to be separated from the autoinhibitory region and produce what is called "stimulated activity" $[7$, 8]. This will expose the substrate binding site in the catalytic domain to complete the activation [8]. Individual subunits of CaMKII are activated separately in the holoenzyme [7]. The conformational change induced by $\mathrm{Ca}^{2+} /$ CaM binding also exposes the conserved T286 phosphorylation site in the autoinhibitory region, allowing it to be phosphorylated by an adjacent, activated subunit. The phosphorylation of T286 prevents the re-binding of the autoinhibitory region to the catalytic domain after $\mathrm{Ca}^{2+}$ / $\mathrm{CaM}$ dissociation. This leads to "constitutive/autonomous activity" [6]. Autophosphorylation of T286 also creates the circumstance of CaM trapping, meaning that the $\mathrm{Ca}^{2+} / \mathrm{CaM}$ complex has reduced dissociation, contributing to more activity of the kinase [8].

CaMKII activity is regulated by both phosphorylation and dephosphorylation events. As described above, autophosphorylation of T286 plays a critical role in regulating CaMKII activity. It also regulates the binding capacity of CaMKII, particularly at the post-synaptic density (PSD) [15]. In addition to T286, CaMKII activity can also be regulated by additional autophosphorylations at T305/ 306 (T306/307 for CaMKII $\beta, \gamma$, and $\delta$ ) and T253 with CaMKII $\alpha$ (T254 for CaMKII $\beta$ ) $[9,16,17]$. As shown in Fig. 1a, T305/306 is located within the $\mathrm{Ca}^{2+} / \mathrm{CaM}$ binding site and can only become phosphorylated when the $\mathrm{Ca}^{2+} /$ $\mathrm{CaM}$ dissociates and autonomous activation is in effect. When this phosphorylation occurs, the $\mathrm{Ca}^{2+} / \mathrm{CaM}$ complex can no longer bind to cause further stimulation of the kinase, leaving the kinase partially active as a result of autonomous activity due to phosphorylated T286 [16]. The phosphorylation of T253 has no direct effect on the kinase activity or $\mathrm{Ca}^{2+} / \mathrm{CaM}$ binding of purified CaMKII in vitro, but affects the targeting of CaMKII via interactions with other binding proteins, therefore has functional effects on cell physiology [9, 16-19]. Dephosphorylation returns the enzyme to an inactive state and is catalyzed by protein phosphatase types 1 and $2 \mathrm{~A}[6,20-23]$.
Major Regulatory Mechanisms of CaMKII

\section{RNA Splicing}

Alternative splicing of the variable region in CaMKII isoforms gives rise to the different subtypes of the kinase [24]. The splicing confers unique properties to certain subtypes of CaMKII isoforms and allows them to regulate distinct cellular processes. The exact numbers of subtypes for each CaMKII isoform and their functions are still an area of active investigation. Based on current knowledge, RNA splicing produces at least three splice variants for CaMKII $\alpha(\alpha, \alpha \mathrm{B}$, and $\alpha \mathrm{KAP})$. The $\alpha$ and $\alpha \mathrm{B}$ subtypes are prevalent in the brain, while the catalytic domain deficient $\alpha$ KAP subtype is predominantly expressed in the skeletal muscle. There are at least six splice variants for CaMKII $\beta$ including $\beta, \beta$, $\beta$ e, and $\beta \mathrm{e}^{\prime}$, which are mainly distributed in the brain. CaMKII $\delta$ has at least eleven splice variants $\left(\mathrm{CaMKII} \delta_{1-11}\right.$, including $\delta_{1 / \mathrm{A}}$, $\delta_{3 / \mathrm{B}}, \delta_{2 / \mathrm{C}}$, and $\delta_{9}$ ), and CaMKII $\gamma$ has at least eight splice variants $\left(\gamma_{\mathrm{A}}-\gamma_{\mathrm{H}}\right)[24,25]$. CaMKII $\gamma$ and CaMKII $\delta$ subtypes can be found in various locations such as the brain, skeletal muscle, heart, and lung $[26,27]$. Within the heart, different $\delta$ subtypes have been shown to function differently, e.g., the nuclear $\mathrm{CaMKII} \delta_{\mathrm{B}}$ controls the expression of the atrial natriuretic factor, and the cytoplasmic $\mathrm{CaMKII} \delta_{\mathrm{C}}$ controls $\mathrm{Ca}^{2+}$ release from the sarcoplasmic reticulum by phosphorylating its cardiac ryanodine receptors $[28,29]$. Certain CaMKII $\gamma$ subtypes contain a nuclear localization sequence (NLS) signal, which plays a role in shuttling $\mathrm{Ca}^{2+} / \mathrm{CaM}$ to the nucleus to enable the activation of the cAMP-response element binding protein in the brain [30]. A detailed review about CaMKII alternative splicing is provided by Sloutsky and Stratton [14].

\section{Subcellular Localization}

The localization of CaMKII in cells plays a crucial role in regulating CaMKII function. It has been well documented that certain subtypes of the CaMKII isoforms are capable of nuclear localization $\left(\alpha \mathrm{B}, \delta_{\mathrm{B}}, \gamma_{\mathrm{A}^{\prime}}\right)$ [30-32]. These CaMKII subtypes share a common core NLS sequence, KKRK, in the variable region to mediate nuclear translocation. This nuclear localization event is also negatively regulated by the phosphorylation of a serine residue immediately adjacent to NLS $[25,30,33]$. Another major regulator of CaMKII localization in cells is the influx of $\mathrm{Ca}^{2+}$. In neurons, $\mathrm{Ca}^{2+}$ influx triggered by glutamate binding to N-methyl-D-aspartate (NMDA) receptors causes translocation of CaMKII to postsynaptic sites and extra-synaptic clusters for regulation of synaptic plasticity [7]. CaMKII can also be mobilized to other subcellular locations such as the cytoskeleton due to CaMKII $\beta$ binding to Factin [34]. Upon $\mathrm{Ca}^{2+}$ influx, CaMKII $\beta$ will dissociate from the $\mathrm{F}$ actin and translocate to the PSD. It is also common to see a heteromeric structure of $\alpha / \beta$-CaMKII bound to F-actin through its interaction with the $\beta$ subunits [35]. 


\section{Oxidative Stress}

Oxidative stress, a condition caused by the overproduction of reactive oxygen species (ROS), can induce oxidative damages on lipids and proteins [36]. ROS has been shown to induce oxidative modifications on a conserved methionine pair M281/282 (C281/M282 in CaMKII $\alpha$ ) in the autoinhibitory region of CaMKII (Fig. 1a) to produce an oxidized form of CaMKII [37]. This oxidation event occurs after $\mathrm{Ca}^{2+}$ activation of the kinase when the autoinhibitory region is removed from the catalytic domain. The oxidized methionine pair will keep the autoinhibitory region from re-binding with the catalytic domain after $\mathrm{Ca}^{2+} / \mathrm{CaM}$ dissociation, which creates an autonomously active state similar to that seen with T286 autophosphorylation [38]. Oxidized CaMKII production is counterbalanced by the activity of methionine sulfoxide reductase A which reduces methionine sulfoxide, product of the first oxidation step. Valine mutation for both methionine oxidation sites of CaMKII reduces atrial fibrillation, similar to methionine sulfoxide reductase overexpression, indicating a pathological role for oxidized CaMKII in cardiac disease [39].

\section{Protein-Protein Interaction}

Protein-protein interactions facilitate the recruitment of CaMKII to different subcellular locations where selective sets of CaMKII substrates are available. Cellular membranes are a major site of protein interactions for CaMKII. In the neurons, one of the most important binding partners of CaMKII is the NMDA receptor subunit GluN2B (NR2B) located at postsynaptic sites, which binds and recruits CaMKII to the synapse after its activation by glutamate stimuli [7]. This interaction is mapped to the T286 site in CaMKII where the accessibility of this site is critical for the binding [40, 41]. A variety of other protein binding partners of CaMKII have also been identified such as the connexin36 which binds and recruits CaMKII to gap junctions [42] and the $\alpha$ subunit of L-type $\mathrm{Ca}^{2+}$ channels which interacts with CaMKII at the plasma membrane [43]. Besides membrane association, CaMKII also binds to a $\mathrm{F}$-actin binding protein $\alpha$ actinin to localize to the cytoskeleton [44].

\section{Non-coding RNAs}

Non-coding RNAs (ncRNA) are functional RNAs but do not encode proteins. ncRNAs play important roles in transcriptional and post-transcriptional regulation of gene expression. Two major groups of ncRNAs, microRNAs which are short RNAs less than 200 nucleotides in length and long noncoding RNAs (IncRNAs) which are longer than 200 nucleotides, have both been implicated in regulating CaMKII gene expression [45]. MicroRNA-145 downregulates the expression of CaMKII $\delta$ in cardiomyocytes and reduces $\mathrm{Ca}^{2+}$ overload [46]. Our group identified two novel $C A M K 2 D$-associated lncRNAs, CAMK2D-associated transcript 1 (C2dat1) and $C A M K 2 D$-associated transcript 2 (C2dat2), that are induced by ischemic insults in the neurons and regulate CaMKII $\delta$ expression in response to ischemia/reperfusion (I/R) $[47,48]$. The mechanisms through which these ncRNAs regulate CaMKII gene expression remain to be fully elucidated.

\section{CaMKII and Cerebrovascular Diseases}

Cerebrovascular disease refers to a group of conditions or disorders that affect the blood vessels in the brain and the cerebral circulation. It is the major cause of long-term disability and stroke, the fifth leading cause of death for Americans [49]. Current studies on CaMKII in this area are mainly focused on three major cerebrovascular diseases, namely cerebral ischemia, $\mathrm{SAH}$, and vascular dementia $(\mathrm{VaD})$. Although we did not find any reports on CaMKII per se in other cerebrovascular diseases, such as intracranial stenosis, aneurysms, vascular malformations, etc., these diseases are common causes of ischemic or hemorrhagic stroke, for example, intracranial stenosis is the narrowing of an artery in the brain, which often leads to ischemic stroke. Similarly, aneurysms and vascular malformations create weak spots on the vessel wall, which can rupture and cause hemorrhagic stroke. In the following sections, we will discuss in details the activity, expression, signaling mechanisms, and functions of CaMKII in the three major cerebrovascular diseases (see Fig. 2 for the key roles and targets of CaMKII in these diseases).

\section{CaMKII and Cerebral Ischemia}

Ischemic stroke accounts for $87 \%$ of all stroke cases in the USA [1]. It results in severe reduction of cerebral blood flow (CBF), lack of oxygen and nutrients in affected brain tissues, induction of excitotoxicity, and the following oxidative damage and post-ischemic inflammation, which ultimately leads to neuronal cell death and brain infarction. Untimely post-stroke reperfusion leads to secondary neuronal injury and harmful effects such as hemorrhagic transformation and blood-brain barrier (BBB) dysfunction in most stroke patients [50, 51]. Basic and translational scientific efforts have therefore been focused on the development and improvement of diagnostic and therapeutic strategies to limit the burden of ischemic insult-induced neuronal and vascular damages, such as neuronal death, BBB dysfunction, cerebrovascular endothelial injury, and vasogenic brain edema $[52,53]$. As previously summarized, all four isoforms of CaMKII are expressed in the brain and regulate a wide range of neuronal and vascular functions [8]. In cerebral ischemia, altered expression and/or activation 


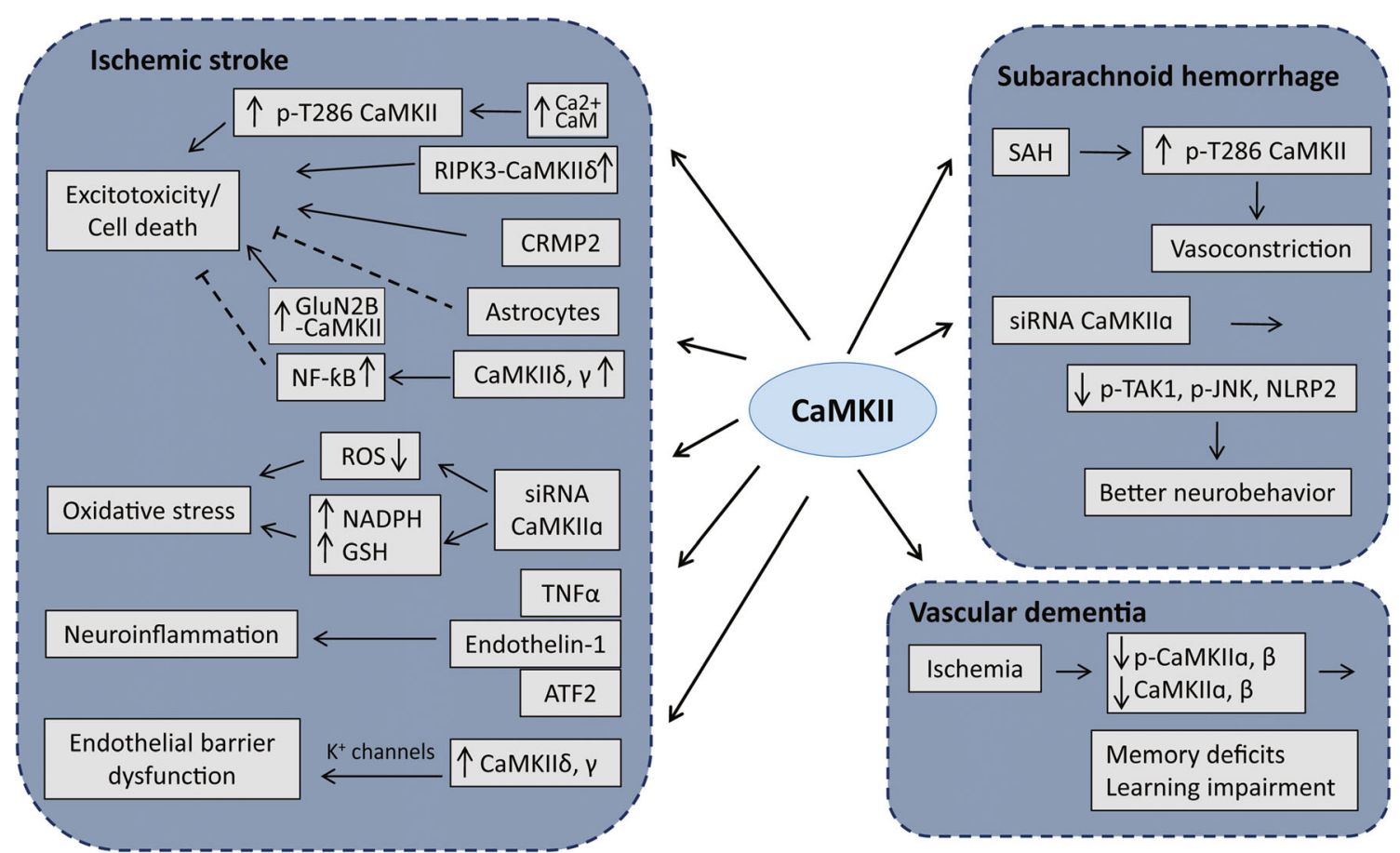

Fig. 2 Schematic representation of key roles of CaMKII in the pathogenesis of cerebrovascular diseases. Aberrant activation or expression of CaMKII contributes to the pathophysiology of ischemic stroke by mediating the core signaling events involved in glutamate excitotoxicity, inflammation, oxidative stress, and endothelial barrier dysfunction. CaMKII is also a major regulator of vessel tone and neuronal plasticity in learning and memory and contributes to pathogenesis of subarachnoid hemorrhage (SAH) and vascular dementia of CaMKII has been considered as a critical contributor of ischemia-induced neuronal cell death, and CaMKII activation can be targeted for both pro- or anti-neuroprotective therapies depending on timing and duration of treatments $[7,8]$.

\section{Altered CaMKII Activity and Expression After Ischemic Stroke}

\section{Glutamate Excitotoxicity-Induced CaMKII Activation and} Translocation Under ischemic stroke conditions, a dramatic drop in oxygen, glucose, and ATP supply leads to uncontrolled neuronal plasma membrane depolarization, release of $\mathrm{K}^{+}$into the extracellular space, and a rapid influx of $\mathrm{Na}^{+}$and $\mathrm{Ca}^{2+}$ into the cells [54]. Neurotransmitters such as glutamate released from depolarized presynaptic and post-synaptic membranes then activate the excitatory NMDA and $\alpha$-amino-3-hydroxy-5-methyl-4-isoxazolepropionic acid (AMPA) receptors [54]. Over-activated NMDA receptors in turn lead to more membrane depolarization and $\mathrm{Ca}^{2+}$ overloading [55]. These alterations will eventually initiate neuronal cell death via programmed cell death (apoptosis) or necrotic pathways and are given the term "glutamate excitotoxicity" [56]. The influx of $\mathrm{Ca}^{2+}$ through NMDA receptors after stroke rapidly activates one of the major $\mathrm{Ca}^{2+}$ sensors in neurons, CaMKII, via binding of $\mathrm{Ca}^{2+} / \mathrm{CaM}$ to its regulatory domain and leads to T286 autophosphorylation which converts it to an autonomously active and $\mathrm{Ca}^{2+} / \mathrm{CaM}$-independent enzyme [57-59]. CaMKII activation and subsequent autophosphorylation can be either a neuronal damaging or pro-survival force in response to ischemic/excitotoxic insults depending on the stroke models and the timing of CaMKII activation which will be discussed in details in the following sections [7, 60].

$\mathrm{I} / \mathrm{R}$ injury leads to rapid activation and translocation of CaMKII in neuronal tissues. Bing-Ren et al. have shown that isolated neocortex protein from rats after global cerebral ischemia (GCI, $15 \mathrm{~min}$ ischemia, followed by $30 \mathrm{~min}, 4 \mathrm{~h}$, and $24 \mathrm{~h}$ reperfusion) exhibited increased CaMKII immunoreactivity and $\mathrm{CaM}$ binding that peaked at $30 \mathrm{~min}$ after reperfusion in the crude synaptosomal fraction of hippocampal CA1 and CA3/DG (dentate gyrus) regions but decreased in the microsomal and cytosolic fractions, suggesting a translocation of CaMKII to synaptosomes [61]. Interestingly, the translocation of CaMKII in the hippocampal CA1 region is sustained for at least $24 \mathrm{~h}$ after reperfusion but partially recovered in CA3/DG [61]. It has been reported by the same group that cerebral ischemia-induced CaMKII translocation to synaptic membranes may enhance neuronal firing rates and $\mathrm{Ca}^{2+}$ influx [62]. Similar observations were reported by Shohei et al. in a rat model of $2 \mathrm{~h}$ middle cerebral artery occlusion (MCAO) followed by $2 \mathrm{~h}$ reperfusion $[63,64]$. In particular, CaMKII $\alpha$ expression in crude synaptosomal fraction increased in the ischemic core area and the surrounding penumbra during ischemia and reperfusion, whereas CaMKII $\alpha$ levels in cytosolic fraction decreased by $20-40 \%$ in the penumbra and by $80 \%$ in the ischemic core area [64]. Meanwhile, 
CaMKII $\alpha$ levels remain unchanged in the whole tissue homogenates from different brain regions $2 \mathrm{~h}$ after reperfusion [64]. Mechanistically, the active conformation (with autophosphorylation of T286) of CaMKII can be sustained after the transient activation by binding to the NMDA receptor subunit GluN2B (also known as NR2B) [40, 60]. This interaction also leads to translocation of CaMKII from the cytosol to the membrane of PSD upon activation [35, 40, 65-67]. Additionally, it has been reported that CaMKII forms extrasynaptic clustering, a self-aggregating process that leads to reduction of CaMKII activity, under ischemic conditions and when stimulated by pathological glutamate stimuli [66-68]. I/ $\mathrm{R}$ also results in increased phosphorylation of CaMKII on T253 in a PSD-enriched fraction prepared from rat hippocampus [18]. Although T253 does not activate CaMKII directly, it may indirectly regulate CaMKII activity by binding to other proteins, which may contribute to the persistent activation of CaMKII involved in ischemia-/excitotoxicity-induced neuronal cell death of a human neuroblastoma cell line (SH-SY5Y) [19]. In general, upon ischemic activation, CaMKII is recruited to synaptic membranes where it may modulate cellular functions that affect cell survival and neurotransmission.

Oxidative Stress-Induced CaMKII Activation In addition to excitotoxicity, cerebral ischemia increases the production of ROS, such as nitric oxide and superoxide, and reperfusion further stimulates ROS generation from neurons and glia cells, resulting in CaMKII oxidation and activation [69]. Erickson et al. reported that M281/282 oxidation leads to a similar conformational change in CaMKII produced by T286 phosphorylation that could maintain CaMKII in an open position to phosphorylate its substrates after $\mathrm{Ca}^{2+} / \mathrm{CaM}$ dissociation [70]. In another study, extracts from mouse forebrain synaptosomes were treated with different oxidizers and immunoblotted under non-reducing conditions with an antibody against CaMKII $\alpha$ showing extensive oxidation of CaMKII forms large molecular weight aggregates and oxidized CaMKII is more closely associated with PSD [71]. To better investigate ischemia-induced oxidation of CaMKII under physiological conditions, the authors soaked acutely prepared mouse hippocampal slices in a modified artificial cerebrospinal fluid buffer pre-saturated with $95 \% \mathrm{~N}_{2} / 5 \% \mathrm{CO}_{2}$ to mimic the ischemia condition, and a similar oxidative modification of CaMKII was observed in the hippocampal slices exposed to ischemic insults [71]. It was also noted in this study that oxidation of CaMKII suppressed both total (in the presence of $\mathrm{Ca}^{2+} / \mathrm{CaM}$ ) and autonomous (independent of $\left.\mathrm{Ca}^{2+} / \mathrm{CaM}\right)$ kinase activities and synaptic potentiation post ischemia due to the formation of large aggregates [71]. CaMKII oxidation has been extensively studied in cardiovascular and pulmonary diseases where oxidative stress drives disease pathology (see a detailed review by Mark E. Anderson [37]). Contrary to the rapid activation of CaMKII, decreased CaMKII activities were also documented in cultured rat hippocampal neurons treated with glutamate [58] and in the rat neocortex, striatum, and hippocampus after forebrain ischemia [72]. The later study also reported that protein levels of CaMKII $\alpha$ and $\beta$ decreased in the cytosol and increased in the particulate fractions of the three brain regions they examined, suggesting an intracellular redistribution of CaMKIIs [72]. Nonetheless, functional outcomes or pathological consequences of excitotoxic/ischemiainduced loss of CaMKII activity were not discussed in these two studies.

Altered CaMKII Expression at Transcriptional Level Besides post-translational regulation by phosphorylation or oxidation, we recently showed that CaMKII could also be regulated at transcriptional level by two lncRNAs, C2dat1 and C2dat2. Wild-type C57BL/6J mice were subjected to $1 \mathrm{~h}$ of MCAO and 6-24 h of reperfusion. C2dat 1 expression was significantly increased in the cortical penumbra at 6-24 h post reperfusion compared to the sham-operated mice. This was also accompanied by an increased expression of CaMKII $\delta$ at transcript and protein levels [47]. Similar expression patterns can be observed in primary mouse neuron cultures under in vitro ischemic condition [47]. Moreover, knockdown of C2dat1 and 2 by siRNAs significantly blocked in vitro ischemiainduced expression of $C a M K 2 D$ in N2a cells and primary neurons. The knockdowns also exacerbated ischemiainduced neuronal cell death [47, 48]. However, knockdown of C2dat 1 and $C 2$ dat 2 had no effects on oxygen-glucose deprivation and reoxygenation $(\mathrm{OGD} / \mathrm{R})$-induced expression of CaMKII $\gamma$, indicating specific targeting of CAMK2D by these IncRNAs [48]. The upregulation of CaMKII $\gamma$ was also interesting as both CaMKII $\delta$ and $\gamma$ were thought to be absent or low in neurons. Knockdown of CaMKIII $\delta$ and $\gamma$ exacerbated OGD/R-induced neuronal cell death, implying that both isoforms promote neuronal survival. This is distinct from its prodeath effects observed in the early phase of $\mathrm{I} / \mathrm{R}$. It is possible that increased CaMKII $\delta$ and $\gamma$ may alter the functionality of CaMKII holoenzyme since their upregulation could change several properties of CaMKII including the ratio of subunit composition in the holoenzyme, stimulated/autonomous activity, localization, and protein interactions.

\section{Contributory Roles of CaMKII in the Pathogenesis of Ischemic Stroke}

Cerebral ischemia triggers a cascade of pathological events that ultimately result in irreversible neuronal injury in stroke-affected brain tissues within minutes of stroke insult [54]. The pathophysiological order of the events ranges from excitotoxicity within minutes, robust inflammatory responses within hours, to programmed cell death and tissue loss within hours and days of stroke onset [54, 73, 74]. Based on our literature search, it appears that most studies have been 
focusing on the involvement of CaMKII in excitotoxicityinduced neuronal death $[7,60,75,76]$. Only a few reported functional roles of CaMKII in inflammation [77], endothelial barrier integrity [3], and astrocyte dysfunction [78] after experimental stroke (summarized in Table 1). In this section, we review the functional inputs of CaMKII in these biological processes.

Excitotoxicity-Induced Cell Death Cerebral ischemia-induced neuronal damage is largely caused by glutamate-mediated excitotoxicity. Synaptic glutamate released from the damaged neurons leads to the activation of NMDA and AMPA receptors $[85,86]$. NMDA receptors are $\mathrm{Ca}^{2+}$ permeable, and the opening of these channels leads to further membrane depolarization and greater $\mathrm{Ca}^{2+}$ influx which exacerbates intracellular $\mathrm{Ca}^{2+}$ overload [86]. Oxygen deprivation-induced acidosis disrupts $\mathrm{Na}^{+} / \mathrm{Ca}^{2+}$ exchanger, prevents the efflux of $\mathrm{Ca}^{2+}$, and further contributes to $\mathrm{Ca}^{2+}$ overload. It is known that $\mathrm{Ca}^{2+}$, at a lower concentration $\left(\sim 10^{-6} \mathrm{M}\right)$, mediates neuroprotective processes, whereas at higher concentration about $10^{-4}-10^{-3}$ $\mathrm{M}, \mathrm{Ca}^{2+}$ induces apoptosis or necrosis $[87,88]$. Prolonged $\mathrm{Ca}^{2+}$ increases during ischemia result in pathophysiological activation of many intracellular signaling cascades, including $\mathrm{Ca}^{2+} / \mathrm{CaM} / \mathrm{CaMKII}$ [88]. CaMKII also phosphorylates NMDA and AMPA glutamate receptors, which further increases $\mathrm{Ca}^{2+}$ influx and aggravates excitotoxicity [88]. These processes contribute to neuronal death during $\mathrm{I} / \mathrm{R}$ but may also contribute to the death of endothelial cells (ECs) [74], astrocytes [89, 90], and oligodendrocytes [81] after cerebral I/R insult or OGD/R. Excitotoxicity may induce cell death mainly by necrotic, apoptotic, or autophagic pathways.

Necrosis Necrosis is generally identified as the cells present swollen organelle phenotypes, which subsequently burst to release their contents into the extracellular space, whereas apoptotic cells undergo nuclear and cytoplasmic condensation, followed by cell fragmentation and phagocytosis by phagocytes [91]. Necrosis occurs during first post-stroke minutes, primarily in the ischemic core [92, 93], whereas apoptosis develops later, for hours or days, mainly in the surrounding penumbra. Overloaded cytosolic $\mathrm{Ca}^{2+}$ can induce necrosis via activation of proteases, phospholipases, and mitochondrial permeability transition [94]. The bestcharacterized form of regulated necrosis is necroptosis. Necroptosis is defined as a necrotic cell death dependent on the kinase activity of Receptor Interacting Protein 1 (RIP1) and RIP3 and expression of mixed lineage kinase-like protein $[94,95]$. Increased RIPK3 expression and RIPK3-CaMKII interaction have been reported in a study in which necroptosis is induced in vitro in oligodendrocyte progenitor cells (OPCs) by OGD plus caspase inhibitor $\mathrm{ZVAD}$ treatment to facilitate cell death from apoptosis to necroptosis [81], whereas RIPK3 siRNA treatment significantly reduced RIPK 3 expression, the

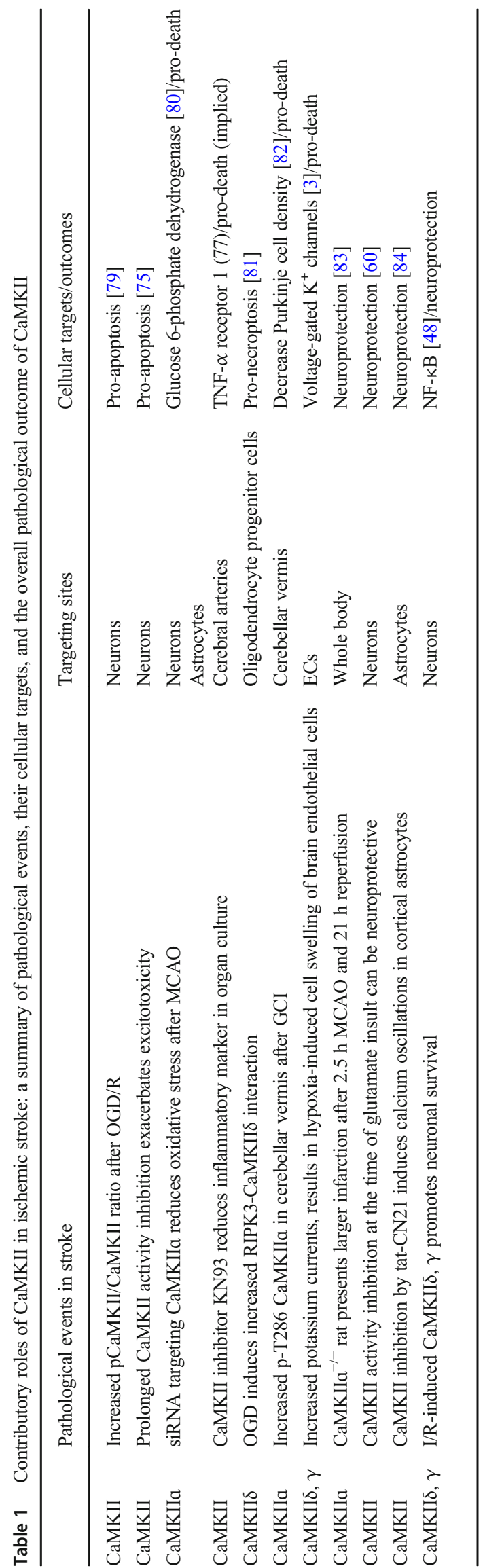


RIPK3-CaMKII $\delta$ interaction, and OPC cell death at $24 \mathrm{~h}$ after OGD [81]. Moreover, activated CaMKII $\delta$ (p-T287) levels were increased in OPCs at 12 and $24 \mathrm{~h}$ after OGD, whereas total CaMKII $\delta$ levels were not altered. Furthermore, RIPK3 inhibition via siRNA decreased p-T287 CaMKII $\delta$ levels [81]. These results suggest that RIPK3 mediates oligodendrocyte necroptosis through interacting with and activating CaMKII $\delta$. In another study by Lixuan et al., they found in a rat model of transient global cerebral ischemia, pretreatment of KN93 (a CaMK inhibitor) before the surgery significantly reduced RIP1 and RIP3 interaction and protected hippocampal neurons from global cerebral ischemia-induced necroptosis [96].

Apoptosis Apoptosis plays a major role in tissue loss in ischemic lesions. Unlike in the ischemic core area of the stroke where neuronal death is generally mediated by necrosis and is considered beyond rescue, apoptosis is the dominating cell death modality in the penumbra [97]. The therapeutic time window between the onset of stroke insult and apoptosisinduced tissue loss surrounding the ischemic site makes it a very attractive target for stroke therapy [97-99]. Diverse apoptotic initiation and regulation pathways are induced in penumbra from different initial triggers and various anti-apoptotic proteins are upregulated as well. CaMKII is found to be upregulated in the penumbra surrounding the infarction core in the rat cerebral cortex at 1, 4, and $24 \mathrm{~h}$ after stroke [99]. Our group has also discovered increased CaMKII $\delta$ fluorescence intensity in the peri-infarct region after I/R [47]. Nicholas et al. reported an increase in CaMKIIa activity (p-T286) in mouse cerebellar vermis at $6 \mathrm{~h}$ after global $\mathrm{I} / \mathrm{R}$ condition. This is believed to contribute to decreased Purkinje cell (a type of neuron located in the cerebellum) densities at 7 days after surgery because it can be inhibited with a single dose of a peptide inhibitor of CaMKII activity, tat-CN19, at $30 \mathrm{~min}$ after surgery [82]. In another in vitro study in which PC12 cells were incubated under OGD condition for $2 \mathrm{~h}$ and then cultured under normal conditions for 1, 2, 4, 5, 12, and $24 \mathrm{~h}$, $\mathrm{pCaMKII/CaMKII}$ ratio increased from $1 \mathrm{~h}$ after incubation in normal conditions, reached maximum at $2 \mathrm{~h}$, and then gradually declined with culturing time but remained higher than non-OGD control group [79]. Cell apoptosis increased in the OGD/R-induced PC12 cells and was blocked by KN93 treatment [79]. These studies suggest that CaMKII activation following I/R contributes to apoptotic cell death. This is consistent with previous studies that have identified a pro-apoptotic role for CaMKII activation following ischemia [18, 19, 100-102] (also summarized by Steven et al. [7]).

Despite the overwhelming evidence supporting a proapoptotic function of CaMKII after I/R, some studies suggest that CaMKII can be neuroprotective by phosphorylating and inhibiting several pro-apoptotic proteins such as NO synthase, Bad, and GSK-3 [7]. In these studies, CaMKII was mostly studied as a whole without distinguishing the specific isoforms involved. Therefore, the role that each CaMKII isoform played in neuronal survival after ischemia remains to be defined. In our studies, both CaMKII $\delta$ and CaMKII $\gamma$ were upregulated in the penumbral tissue from 1 to 4 days after MCAO surgery [47, 48]. Overexpression of CaMKII $\delta$ promoted neuronal survival in the OGD/R model, while knockdown of CaMKII $\gamma$ resulted in significant neuronal death after OGD/R [48]. We also demonstrated that I/R-induced CaMKII $\delta$ and CaMKII $\gamma$ promoted neuronal survival through activating the canonical NF- $\kappa \mathrm{B}$ signaling pathway [48]. It is notable that the induction of CaMKII $\delta$ by lncRNAs was gradual and persistent which is distinct from the acute activation of CaMKII immediately after I/R that often associates with neuronal death, highlighting the dynamic regulation and functional diversity of the CaMKII kinases in the course of I/R injury in the brain. In line with the pro-survival function of CaMKII, there are also studies that suggest that prolonged inhibition or knockout of CaMKII exacerbates ischemic injuries [60, 75, 83]. For example, genetic knockout of CaMKIIa resulted in larger infarction compared to wild-type littermates in a MCAO model [83]. This finding could be explained by the developmental defects caused by lacking CaMKIIa since it was reported by another group that CaMKIIa knockout mice are epileptic [103], meaning the KO mice are generally more susceptible to ischemic insults. The Hudmon group showed that prolonged pharmacological inhibition of CaMKII (incubate with tat-CN21 for 4-24 h) exacerbated excitotoxicity following glutamate/glycine insult in cultured neurons [60]. They further confirmed that cultured neurons underwent apoptosis in response to prolonged CaMKII inhibition ( $>4 \mathrm{~h}$ ) since the prolonged CaMKII inhibition was associated with an increase in TUNEL staining and caspase-3 cleavage [75]. These findings are consistent with the notion that the extent of neuronal damage in the penumbra depends on the level of CaMKII, and loss of CaMKII augments neuronal susceptibility to ischemic insults.

Autophagy Excitotoxic insults also lead to neuronal autophagy, and accumulating studies have indicated autophagy is involved in the pathophysiological changes in ischemic stroke [104, 105]. Interestingly, autophagy can play both protective and detrimental roles in ischemic stroke which are summarized in a review article by Pei et al. [106]. CaMKII has been shown to regulate autophagy in neuroblastoma cells. Li et al. reported that CaMKII can directly phosphorylate Beclin-1 (a critical regulator of autophagy) to promote the activation of autophagy [107]. CaMKII has also been shown to regulate autophagy in myocardial I/R injury. Kong et al. demonstrated that CaMKII inhibition attenuated autophagic flux through mitigating the phosphorylation of Beclin-1 [108]. In addition, Kulbe et al. found that tat-CN21, a highly selective peptide inhibitor of CaMKII with neuroprotective function [109], inhibited basal autophagy in primary hippocampal 
neurons [110]. However, in the presence of excitotoxic glutamate insults that blocked autophagy, no further effects were observed after tat-CN21 treatment [110]. Taken together, although a promising target, more investigations are needed to define the role of CaMKII and its regulatory mechanisms in autophagy in cerebral I/R injury.

Neuroinflammation Cerebral ischemia induces a cascade of molecular events that transform the cerebrovascular endothelium from a quiescent to a proinflammatory state [111]. Activated cerebral endothelium have the capacity to produce and/or secrete many inflammatory mediators, most important of which are the selectins, proinflammatory cytokines, and integrins, thus becoming a source of inflammation themselves in the cerebral vasculature [112]. Tumor necrosis factor alpha $(\mathrm{TNF}-\alpha)$ is one of the proinflammatory cytokines that initiates inflammation in many cell types via its receptor (TNF- $\alpha$ receptor 1) and plays an essential role in cerebrovascular inflammation. Using the method of organ culture for inducing ischemic-like vascular wall changes, Roya et al. incubated rat basilar arteries in serum-free medium for $0,3,6$, or $24 \mathrm{~h}$ in the presence or absence of CaMKII inhibitor KN93 [77]. They found CaMKII activation in the non-incubated $(0 \mathrm{~h})$ arteries was gradually decreased with time. The TNF- $\alpha$ receptor 1 expression was elevated after organ culture and can be blocked by treatment of CaMKII inhibitor KN93 [77]. Their findings suggest that inhibiting CaMKII activation attenuates neuroinflammatory mediators and could contribute to neuroprotection. The elevation of another proinflammatory mediator, endothelin-1 (ET-1), has been indicated in the regions of vascular injuries and inflammation [113]. In mouse brain microvascular endothelial cells bEnd.3, Chih-Chung et al. found that ET-1 stimulated increases of intracellular $\mathrm{Ca}^{2+}$. This contributed to ET-1-induced CaMKII activation and ET-1/ET receptor-mediated cyclooxygenase-2/prostaglandin E2 release (both are known to aggravate brain inflammation) through regulating mitogen-activated protein kinases and the downstream activating transcription factor 2 [114]. Both studies suggest that strategies targeting CaMKII may be beneficial for brain injury and inflammatory disease.

Oxidative Stress-Induced Tissue Damage Many pathological events occur during the ischemia reperfusion procedure, including the release of free radicals that bring damages to the brain and aggravate neuronal injuries. These free radicals represented by ROS could spark oxidative stress in the brain. With the help of glutathione reductase and nicotinamide adenine dinucleotide phosphate (NADPH), oxidized glutathione can be transformed to reduced glutathione, which is necessary to eliminate excess ROS [115]. Previous studies indicate that CaMKII can be activated by ROS, and activated CaMKII also regulates redox regulators such as NADPH and reduced glutathione to further exacerbate oxidative stress-induced tissue damage [37], providing a potential feed-forward cycle for CaMKII to infuse the oxidative stress-induced tissue damage. In a rat ischemic stroke model, Yamin et al. performed intracerebroventricular injection of siRNA that targets CaMKII $\alpha$ at $48 \mathrm{~h}$ pre-MCAO surgery. They found rats that received siRNA injection showed milder neurological deficits and smaller infarct volume compared to those that received scramble control injection [80]. In addition, CaMKII $\alpha$ siRNA decreased ROS content and increased the reduced glutathione/ oxidized glutathione and NADPH/NADP ${ }^{+}$ratios in the rat cortex after MCAO [80], suggesting that CaMKII $\alpha$ inhibition could suppress oxidative stress through upregulating NADPH and reduced glutathione. This study provides evidence that CaMKII inhibition can serve as anti-oxidant therapy in cerebrovascular disease.

Endothelial Barrier Dysfunction Endothelium plays a critical role in the regulation of vascular function. Untimely reperfusion after ischemic stroke often times leads to harmful consequences including blood-brain barrier (BBB) dysfunction. BBB is centrally positioned within the neurovascular unit, and several elements contribute to the physical barrier of BBB, including cerebrovascular ECs, junctional proteins, pericytes, astrocytes, and basement membrane [53]. Among those, cerebrovascular ECs are the primary barrier between circulation and tissue that play an essential role in the maintenance of BBB integrity/permeability and cerebral homeostasis. CaMKII $\alpha$ was found in the perinuclear region of the cells in primary cerebral EC culture [116]. In a separate study, glutamate treatment induced CaMKII $\alpha$ activation in primary cultures of rat cerebral ECs even after 10and 60-min recovery [59]. Besides CaMKII $\alpha$, both CaMKII $\delta$ and $\gamma$ are expressed in rat brain capillary ECs. Moreover, activation of CaMKII $\delta$ and $\gamma$ was found upstream of voltage-gated potassium channels, resulting in hypoxia-induced cell swelling that may precede barrier dysfunction [3]. In addition, CaMKII $\delta$ and $\gamma$ were found in human central nervous system pericytes, and their activation is required for extracellular acidosis-induced cAMP-response element binding protein activation and proinflammatory cytokine interleukin-6 upregulation [4]. CaMKII is also found expressed in cultured cortical astrocytes using panCaMKII antibody [84]. To mimic the rapid loss of CaMKII activity in brain tissue during an ischemic insult, cultured cortical astrocytes were treated with CaMKII inhibitor tat-CN21. Inhibiting CaMKII activity in neuronal support cells (astrocytes) induces ATP release from astrocytes and contributes to $\mathrm{Ca}^{2+}$ oscillations in astrocytes and induces neuronal death [84]. However, functional roles of CaMKII in regulating endothelial barrier function in vivo remain to be explored. 


\section{Inhibitors of CaMKII and Their Effects on Post-insult Neuroprotection}

Given the well-documented CaMKII activation immediately after ischemic insults and its role in mediating neuronal death in experimental models of stroke, it appears to be a promising target for acute clinical intervention to limit brain damage after stroke. Small molecule CaMKII inhibitors KN62 and KN93 have been widely used to study CaMKII function in vitro, as they are membrane penetrating [7]. However, KN inhibitors are not selective inhibitors for CaMKII activation [117]. A more selective CaMKII inhibitor is CN21, which is a $21 \mathrm{mer}$ peptide derived from the natural CaMKII inhibitory protein CaM-KIIN [118]. Peptide-based inhibitors are further made cell penetrating by fusion with a sequence motif such as tat [119]. Inhibiting stimulated and autonomous CaMKII activity with tat-CN21 attenuated neuronal cell death after a glutamate insult in vitro or in vivo and was effective even when administered $1 \mathrm{~h}$ after the MCAO surgery, which is within a clinically relevant window of therapeutic opportunity [109]. In a separate study in which KN93, tat-AIP, and tat-CN21 were applied either immediately before or after the excitotoxic insult, post-insult neuroprotection by CaMKII inhibition was confirmed using both tat-CN21 and tat-AIP, but not KN93 [60]. This study also confirmed significant neuroprotection in cortical cultures when tat-CN21 was administered $2 \mathrm{~h}$ after excitotoxic challenge. On the contrary, KN93 was neuroprotective only when administered during but not after the insult in both studies [60, 109]. In a rat GCI model, tat-CN21 administered $3 \mathrm{~h}$ after reperfusion exerted neuroprotective effects against delayed hippocampal CA1 pyramidal neuronal cell death 10 days post GCI through decreasing GCI-induced phosphorylation, translocation, and membrane targeting of CaMKIIa, as well as CaMKIIa-NR2B interaction [102]. Mechanistically, tat-CN21 and tat-AIP can both block $\mathrm{Ca}^{2+}$ / CaM-stimulated activity of CaMKII and the $\mathrm{Ca}^{2+}$-independent autonomous CaMKII activity during the insult, whereas KN93 only inhibits $\mathrm{Ca}^{2+} / \mathrm{CaM}$-stimulated CaMKII activity effectively, suggesting that the autonomous activation of CaMKII may be a promising drug target for post-stroke neuroprotection. However, both KN93 and AIP have been shown to have off-target effectors. KN93 is an inhibitor of several CaMK family members including CaMKI, CaMKII, CaMKIV, and voltage-gated $\mathrm{K}^{+}$and $\mathrm{Ca}^{2+}$ channels [60]. The peptide inhibitor AIP has also been shown to inhibit other CaMK family members [60].

Interestingly, using a competitive inhibitor of CaMKII kinase activity to inhibit ischemia-induced sustained activation of CaMKII may lead to opposite effects. For example, tatCN21 treatment for $8 \mathrm{~h}$ or more before the glutamate insult resulted in a significant increase of neuronal death in cortical cultures compared to glutamate insult alone [60]. In an in vitro study, tat-CN21 treatment in cortical astrocytes decreased glutamate uptake, increased ATP release, and dysregulated astrocyte-neuron signaling thereby compromising neuronal survival after ischemic insult [84]. These studies are again in line with the previous observation that $\mathrm{CaMKIIa}^{-/-}$mice had larger infarction than the wild-type mice after MCAO [83]. Overall, CaMKII inhibition-mediated neuroprotection was achieved when inhibitors were administered at the acute phase of ischemic/excitotoxic insults, whereas sustained CaMKII inhibition long $(>4 \mathrm{~h}$ ) before ischemic insult could exacerbate neuronal death by enhancing neuronal vulnerability to the insults.

\section{CaMKII and Subarachnoid Hemorrhage}

Hemorrhagic stroke is caused by rupture of weakened arterial blood vessels, causing bleeding and damage to the surrounding brain tissue. There are two types of hemorrhagic stroke; the most common type is intracerebral hemorrhage (ICH) that occurs within the brain tissue, and the less common type is subarachnoid hemorrhage (SAH). There have not been any studies on CaMKII in ICH. Therefore, we mainly discuss the role of CaMKII in SAH in this section. Approximately $80 \%$ of non-traumatic, spontaneous $\mathrm{SAH}$ is due to the rupture of an intracranial aneurysm leading to the extravasation of arterial blood into subarachnoid space [120]. The initial mortality in SAH patients before receiving medical attention is high (12\%) [121]. After several days, the development of delayed cerebral ischemia and cerebral vasospasm contributes to a prolonged $\mathrm{CBF}$ reduction in approximately $40 \%$ of $\mathrm{SAH}$ patients [122]. Of those patients who survive SAH, many of them suffer from long-term memory and cognitive defects that severely impact their quality of life [123].

Early brain injury (first $72 \mathrm{~h}$ after $\mathrm{SAH}$ ) could happen within minutes after the initial bleeding, mostly due to ischemia, based on a large body of animal studies [124, 125]. A study by Parker et al. utilized quantitative mass spectrometrybased phosphoproteomic analysis to dissect early SAHinduced phosphorylation events $(0.5 \mathrm{~h}$ and $1 \mathrm{~h}$ post $\mathrm{SAH})$ in cerebral artery tissue lysates from SAH rats [126]. Among those protein kinases significantly altered by SAH, they found CaMKII activation at its autophosphorylation site T286 which could be blocked by treating the rat with KN93 prior to SAH. However, the total CaMKII expression remained unchanged [126], implying that CaMKII might play a role in SAHinduced cerebral vasculopathy. In agreement with Benjamin's study, Lars et al. also observed a rapid activation of CaMKII at its autophosphorylation site T286 at $1 \mathrm{~h}$ post $\mathrm{SAH}$ in rat cerebral artery lysates, and the activated CaMKII reduced to sham-operated levels at 6 and $24 \mathrm{~h}$ post SAH [127]. They also observed an increased overall CaMKII protein expression at $72 \mathrm{~h}$ post SAH by immunohistochemistry in cerebral vascular smooth muscle cells. Interestingly, this can be blocked by KN93 treatment prior and immediately after SAH 
operation [127]. Moreover, KN93 treatment attenuated endothelin and serotonin receptor-mediated vasoconstriction and improved sensorimotor function at $48 \mathrm{~h}$ post SAH. Therefore, inhibiting CaMKII activation by KN93 can be beneficial through reducing cerebral vasoconstriction and improving neurological outcomes after SAH [127]. The beneficial effects through inhibiting CaMKII activity were further affirmed by another group using siRNA that targets CaMKII $\alpha$ [128]. The expression of activated CaMKII $\alpha$ in rat brain increased from 3 to $24 \mathrm{~h}$ post SAH (total CaMKII $\alpha$ expression did not change), and p-CaMKII $\alpha$ (T286) mainly localized within the neurons and microglia [128]. Meanwhile, CaMKII $\alpha$ knockdown by siRNA injected intracerebroventricularly at $48 \mathrm{~h}$ prior to surgery, markedly improved neurobehavior after SAH [128] and significantly decreased p-TAK1, p-JNK, and nucleotide-binding domainlike receptor protein 3 (NLRP3) inflammasome expression (indicating reduced inflammatory response). Sang et al. reported that 6 days after SAH injury, CaMKII overall expression was reduced in the dendritic layer of the CA1 area of the hippo-pyramidal cells. This was accompanied by a significant decrease of synapses in neurons in the CA1 area that could be responsible for loss of long-term potentiation (a persistent strengthening of synapses following high levels of neuronal stimulation) after SAH [129]. Taken together, SAH-induced CaMKII activation or overall expression can vary depending on different brain regions, cell types, $\mathrm{SAH}$ models, and time after SAH surgery. Nonetheless, inhibition of CaMKII activity mostly associates with improved neurological outcome after SAH.

\section{CaMKII and Vascular Dementia}

Vascular dementia (VaD) is a complex neurodegenerative disorder that is manifested as the functional consequence of reduced blood flow (acutely or chronically) in the brain [130]. $\mathrm{VaD}$ associates with a progressive cognitive and memory impairment, and the instances increase with age [131]. While CaMKII is highly enriched in neuronal tissue (especially in hippocampal pyramidal cells), the autophosphorylation of CaMKII is deemed essential for the hippocampus-dependent memory formation and the long-lasting increase in synaptic efficacy following long-term potentiation [132]. The activation and functional involvement of CaMKII signaling in the hippocampus and other brain regions has been well documented in different animal $\mathrm{VaD}$ models.

Most studies focus on the neuroprotective function of CaMKII in hippocampal CA1 pyramidal neurons and the restored learning and memory ability in $\mathrm{VaD}$ animals through activating CaMKII. For example, in a VaD mouse model, Yui et al. reported a cerebral ischemia-induced contextual memory deficit, and both activated CaMKII (including $\alpha$ and $\beta$ isoforms) and the total CaMKII $\alpha$ and CaMKII $\beta$ expressions were significantly decreased in the hippocampal CA1 region at 12 days in bilateral common carotid artery occlusion (BCCAO) mice [133]. Under certain BCCAO conditions, they found nobiletin (a compound for Alzheimer's disease therapy) treatment inhibited delayed neuronal death and restored both CaMKII ( $\alpha$ and $\beta$ ) activation and the overall expression in the hippocampal CA1 region. Nobiletin also improved BCCAO-induced memory deficits and hippocampal long-term potentiation impairment [133]. Xiao-Juan et al. reported similar observations that cerebral ischemia led to reduced p-CaMKII (T286) in the hippocampal CA1 pyramidal neurons, which associates with decreased spatial learning and memory capacity of mice subjected to right unilateral common carotid artery occlusion (a chronic VaD model) at 30 days after surgery [134]. These deficits can be partially rescued by CaM antagonist loaded micelle treatment [134]. The same group reported in another study using a bilateral common carotid artery stenosis mouse model (BCCAS, a common model of cerebral hypoperfusion-induced cognitive impairment) that CaM inhibitor DY-9836 restored the decrease of p-CaMKII (T286) in hippocampal pyramidal neurons and improved learning impairment after BCCAS surgical operation [135]. Similar results were reported in a rat permanent BCCAO model $[136,137]$. In addition, $\mathrm{VaD}$ is an agerelated disease. Qi et al. explored aging-induced cognitive deficits in a senescence-accelerated mouse (SAMP8) model [138], in which the cognitive deficits can be observed as early as 4 months after birth [139]. A significant decrease in pCaMKII $\alpha$ (T286) but not the non-phosphorylated CaMKII $\alpha$ expression, was observed in the prefrontal cortex region of older SAMP8 mice compared to the younger SAMR1 mice [138], and oral administration of a traditional Chinese prescription, Kangen-karyu, ameliorated aging-induced memory deficits and restored $\mathrm{p}-\mathrm{CaMKII} \alpha$ expression in the cerebral cortex of older SAMP8 mice [138]. Despite the variety of $\mathrm{VaD}$ models employed in different studies, it appears that they all come to the same conclusion that restoring p-CaMKII (T286) or CaMKII overall expression is beneficial for cerebral ischemia-/age-induced cognitive deficits.

\section{Summary and Future Prospects}

In this article, we reviewed the important roles of CaMKII serine/threonine kinases in cerebrovascular diseases. There are both well-studied and under-studied areas of CaMKII functions in stroke, subarachnoid hemorrhage, and vascular dementia (summarized in Table 2). The four isoforms of CaMKII, although highly conserved in domain structures, vary widely in expression patterns in different tissues and exhibit significant pathobiological functional diversity in cerebrovascular diseases. In light of all the literature on this topic, we have come to the conclusion that CaMKIIs 
Table 2 CaMKII studies in cerebral vascular diseases: a summary of well-studied and under-studied areas of CaMKII in major cerebral vascular diseases

\begin{tabular}{|c|c|c|}
\hline CaMKII & Well-studied & Under-studied \\
\hline $\begin{array}{r}\text { Ischemic } \\
\text { stroke }\end{array}$ & $\begin{array}{l}\text { - Changes of CaMKII } \\
\text { activity, expression, and } \\
\text { localization before and } \\
\text { after ischemic stroke } \\
\text { - Ischemia-induced } \\
\text { CaMKII oxidation } \\
\text { - Role of CaMKII } \\
\text { holoenzyme or } \\
\text { CaMKII } \alpha \text { in } \\
\text { ischemia-induced apo- } \\
\text { ptotic neuronal cell } \\
\text { death } \\
\text { - CaMKII in } \\
\text { excitotoxicity-induced } \\
\text { neuronal death in ische- } \\
\text { mic stroke } \\
\text { - Effects of CaMKII } \\
\text { inhibitors on post-insult } \\
\text { neuroprotection }\end{array}$ & $\begin{array}{l}\text { - Signaling mechanisms of } \\
\text { CaMKII in neurons and } \\
\text { non-neuronal cells in is- } \\
\text { chemic stroke } \\
\text { - Functions of CaMKII in } \\
\text { non-neuronal cells such } \\
\text { as vascular endothelial } \\
\text { cells } \\
\text { - Involvement of CaMKII } \\
\text { in neuroinflammation } \\
\text { and endothelial barrier } \\
\text { dysfunction induced by } \\
\text { ischemic insults } \\
\text { - Roles of under-studied } \\
\text { CaMKII isoforms such } \\
\text { as } \delta \text { and } \gamma \text { in ischemic } \\
\text { stroke } \\
\text { - CaMKII regulation by } \\
\text { non-coding RNAs } \\
\text { - Translation of } \\
\text { CaMKII-targeted agents } \\
\text { to clinical settings }\end{array}$ \\
\hline $\begin{array}{c}\text { Subarachnoid } \\
\text { hemor- } \\
\text { rhage }\end{array}$ & $\begin{array}{l}\text { - Changes of CaMKII } \\
\text { expression and activity } \\
\text { before and after SAH } \\
\text { - Impact of CaMKII } \\
\text { activation on } \\
\text { neurological outcome } \\
\text { after SAH }\end{array}$ & $\begin{array}{l}\text { - How CaMKII contributes } \\
\text { to improved neurological } \\
\text { outcome after SAH } \\
\text { - Functional involvement } \\
\text { and signaling } \\
\text { mechanisms of CaMKII } \\
\text { in neurons and } \\
\text { non-neuronal cells after } \\
\text { SAH }\end{array}$ \\
\hline $\begin{array}{l}\text { Vascular } \\
\text { dementia }\end{array}$ & $\begin{array}{l}\text { - Activation and } \\
\text { neuroprotective } \\
\text { function of CaMKII in } \\
\text { hippocampal neurons in } \\
\text { different animal VaD } \\
\text { models }\end{array}$ & $\begin{array}{l}\text { - Mechanisms of CaMKII } \\
\text { activation/upregulation } \\
\text { in VaD } \\
\text { - Functional involvement of } \\
\text { CaMKII in non-neuronal } \\
\text { cells in VaD models }\end{array}$ \\
\hline
\end{tabular}

significantly influence the pathological processes of cerebrovascular diseases by regulating a whole host of events and neurovascular cells including neurons, ECs, smooth muscle cells, pericytes, and astrocytes. In addition to the most extensively studied isoform CaMKIIa, which is a neuron-specific isoform, the understudied CaMKII isoforms (CaMKII $\delta$ and $\gamma$ ) have also emerged as new players in neuronal recovery after ischemic insults $[47,48,81]$. Overall, in ischemic stroke, there is compelling evidence supporting rapid CaMKII activation immediately after I/R insults, and activated CaMKII plays a crucial role in mediating excitotoxicity-induced neuronal death through necrotic, apoptotic, and possibly autophagic pathways and contributes to secondary oxidative damage, neuroinflammation, and BBB dysfunction, indicating that inhibition of CaMKII may be a promising therapeutic strategy to limit brain damage in acute phase of ischemic injury. However, there remain discrepancies in the role of CaMKII in later phases of ischemic stroke with evidence showing that prolonged inhibition or loss of CaMKII compromises neuronal function and survival, suggesting a positive role of CaMKII in neuronal recovery. In SAH, despite the varied CaMKII activity and expression in different brain regions after hemorrhagic injury, inhibition of CaMKII activity has consistently resulted in improved neurological outcome after SAH, supporting a pro-death function of CaMKII in SAH. In contrast, results from various $\mathrm{VaD}$ models have consistently demonstrated that increased p-CaMKII (T286) or CaMKII overall expression reduces cerebral ischemia-/age-induced cognitive deficits, implying that restoration of CaMKII activity and expression may benefit $\mathrm{VaD}$ patients. From a therapeutic perspective, the timing and duration of CaMKII inhibition will need to be calibrated carefully since inhibitors administered at the acute phase of $I / R$ may be neuroprotective, while those resulted in long periods of sustained CaMKII inhibition could exacerbate neuronal death. Additionally, CaMKII inhibitors that block autonomous activation of CaMKII clearly provide added advantage for post-stroke neuroprotection, such as tat-CN21 which is a selective and efficacious CaMKII inhibitor that blocks both stimulated and autonomous activity of CaMKII in vitro and in vivo.

Although previous studies have implied the effectiveness of neuroprotectant in animal stroke models, there has not been much progress made by far in regard to the successful translation of neuroprotective strategies to clinical settings [73], suggesting that focusing only on neuroprotection is insufficient. In other words, non-neuronal cells and the local microenvironment of the surviving neurons could serve as potential therapeutic targets to alleviate ischemic brain injuries as well. For example, cerebrovascular ECs play an essential role in the maintenance of BBB integrity and cerebral homeostasis under physiological conditions [140, 141]. Ischemia-induced endothelial injury increases cerebrovascular permeability and compromises BBB integrity. Proinflammatory factors may then pass through the compromised BBB to attract circulating immune cells to the injured brain which leads to secondary ischemic brain parenchymal injuries [142]. Studies by Ferenc group indicated that CaMKIIa, $\delta$, and $\gamma$ are all expressed in murine cerebrovascular ECs [59, 116], and Blasig group further reported that hypoxia induced activation of CaMKII $\delta$ and $\gamma$ in rat brain capillary ECs associated with cell swelling that may precede barrier dysfunction [3]. Based on this previous evidence, it would be of great interest to explore whether CaMKII is one of the upstream molecular regulators of BBB stability, dysfunction, or protection after cerebral ischemia. Moreover, studies in rodent cerebral ischemia models have demonstrated that cerebral vascular ECs begin to proliferate in the peri-infarct regions as early as $12 \mathrm{~h}$ after stroke onset [143]. Importantly, the extent of angiogenesis is often closely associated with reduced cerebral infarction and improved neurological recovery [143]. Thus, studying whether CaMKII activity is 
involved in post-ischemic angiogenesis may be a useful therapeutic strategy for treatment of ischemic stroke in clinical settings.

With the help of advanced techniques such as genetic manipulation, genomic editing, and proteomics, more comprehensive and in-depth understanding of CaMKII's roles in cerebrovascular diseases will be conducive to develop novel therapeutic approaches to effectively reduce the risk of cerebrovascular diseases, as well as improve prognosis and decrease complications.

Abbreviations CaMKII, $\mathrm{Ca}^{2+} /$ calmodulin-dependent protein kinase II; $\mathrm{CaM}$, calmodulin; $\mathrm{CBF}$, cerebral blood flow; $\mathrm{BBB}$, blood-brain barrier; MCAO, middle cerebral artery occlusion; OGD, oxygen and glucose deprivation; NLS, nuclear localization sequence; PSD, post-synaptic density; ROS, reactive oxygen species; lncRNA, long non-coding RNA; GCI, global cerebral ischemia; EC, endothelial cell; SAH, subarachnoid hemorrhage; $\mathrm{VaD}$, vascular dementia; $\mathrm{BCCAO}$, bilateral common carotid arteries occlusion; NMDA, N-methyl-D-aspartate; AMPA, $\alpha$-amino-3hydroxy-5-methyl-4-isoxazolepropionic acid; NADPH, nicotinamide adenine dinucleotide phosphate; TNF- $\alpha$, tumor necrosis factor alpha; ET-1, endothelin-1

Author Contribution Q. Jane Wang had the idea for the article and directed the drafting and revising of the work, Xuejing Zhang and Jaclyn Connelly performed the literature search and data analysis and drafted the work, and Edwin S. Levitan and Dandan Sun participated in drafting and critically revising the manuscript.

Funding This work was supported in part by the American Heart Association award 19TPA34850096 (Wang) and NIHR01NS48216 (Sun).

Data Availability All data and materials are available and support the published claims and comply with field standards.

Code Availability Not applicable. No coding in the study.

\section{Declarations}

Ethics Approval This is a review paper. No ethical approval is required.

Consent to Participate Informed consent was obtained from all individual participants included in the study.

Consent for Publication This is a review paper. No participants involved in the study.

Conflict of Interest The authors declare no competing interests.

Open Access This article is licensed under a Creative Commons Attribution 4.0 International License, which permits use, sharing, adaptation, distribution and reproduction in any medium or format, as long as you give appropriate credit to the original author(s) and the source, provide a link to the Creative Commons licence, and indicate if changes were made. The images or other third party material in this article are included in the article's Creative Commons licence, unless indicated otherwise in a credit line to the material. If material is not included in the article's Creative Commons licence and your intended use is not permitted by statutory regulation or exceeds the permitted use, you will need to obtain permission directly from the copyright holder. To view a copy of this licence, visit http://creativecommons.org/licenses/by/4.0/.

\section{References}

1. Benjamin EJ, Blaha MJ, Chiuve SE, Cushman M, Das SR, Deo R, et al. Heart disease and stroke statistics-2017 update: a report from the American Heart Association. Circulation. 2017;135(10):e146-603.

2. Le Roux PD, Winn HR. Management of cerebral aneurysms. How can current management be improved? Neurosurg Clin N Am. 1998;9(3):421-33.

3. Balla Z, Hoch B, Karczewski P, Blasig IE. Calcium/calmodulindependent protein kinase IIdelta 2 and gamma isoforms regulate potassium currents of rat brain capillary endothelial cells under hypoxic conditions. J Biol Chem. 2002;277(24):21306-14.

4. Nakamura K, Kamouchi M, Arimura K, Nishimura A, Kuroda J, Ishitsuka $\mathrm{K}$, et al. Extracellular acidification activates cAMP responsive element binding protein via $\mathrm{Na}+\mathrm{H}+$ exchanger isoform 1-mediated $\mathrm{Ca}(2)(+)$ oscillation in central nervous system pericytes. Arterioscler Thromb Vasc Biol. 2012;32(11):2670-7.

5. Bayer KU, Schulman H. CaM kinase: still inspiring at 40 . Neuron. 2019;103(3):380-94.

6. Lisman J, Schulman H, Cline H. The molecular basis of CaMKII function in synaptic and behavioural memory. Nat Rev Neurosci. 2002;3(3):175-90.

7. Coultrap SJ, Vest RS, Ashpole NM, Hudmon A, Bayer KU. CaMKII in cerebral ischemia. Acta Pharmacol Sin. 2011;32(7): 861-72.

8. Toussaint F, Charbel C, Allen BG, Ledoux J. Vascular CaMKII: heart and brain in your arteries. Am J Physiol Cell Physiol. 2016;311(3):C462-C78.

9. Rostas JAP, Spratt NJ, Dickson PW, Skelding KA. The role of $\mathrm{Ca}(2+)$-calmodulin stimulated protein kinase II in ischaemic stroke - a potential target for neuroprotective therapies. Neurochem Int. 2017;107:33-42.

10. Ebenebe OV, Heather A, Erickson JR. CaMKII in vascular signalling: "friend or foe"? Heart Lung Circ. 2018;27(5):560-7.

11. Bhattacharyya M, Stratton MM, Going CC, McSpadden ED, Huang Y, Susa AC, et al. Molecular mechanism of activationtriggered subunit exchange in $\mathrm{Ca}(2+) /$ calmodulin-dependent protein kinase II. Elife. 2016;5:e13405.

12. Bhattacharyya M, Karandur D, Kuriyan J. Structural Insights into the regulation of $\mathrm{Ca}(2+) /$ calmodulin-dependent protein kinase II (CaMKII). Cold Spring Harb Perspect Biol. 2020;12(6):a035147.

13. Tombes RM, Faison MO, Turbeville JM. Organization and evolution of multifunctional $\mathrm{Ca}(2+) / \mathrm{CaM}$-dependent protein kinase genes. Gene. 2003;322:17-31.

14. Sloutsky R, Stratton MM. Functional implications of CaMKII alternative splicing. Eur J Neurosci. 2020. https://doi.org/10. 1111/ejn.14761.

15. Strack S, Colbran RJ. Autophosphorylation-dependent targeting of calcium/ calmodulin-dependent protein kinase II by the NR2B subunit of the N-methyl-D-aspartate receptor. J Biol Chem. 1998;273(33):20689-92.

16. Skelding KA, Rostas JAP Regulation of multifunctional calcium/ calmodulin stimulated protein kinases by molecular targeting $\mathrm{Ch}$. (2020) 26.(Springer Nature Switzerland AG).

17. Migues PV, Lehmann IT, Fluechter L, Cammarota M, Gurd JW, Sim AT, et al. Phosphorylation of CaMKII at Thr253 occurs 
in vivo and enhances binding to isolated postsynaptic densities. J Neurochem. 2006;98(1):289-99.

18. Gurd JW, Rawof S, Zhen Huo J, Dykstra C, Bissoon N, Teves L, et al. Ischemia and status epilepitcus result in enhanced phosphorylation of calcium and calmodulin-stimulated protein kinase II on threonine 253. Brain Res. 2008;1218:158-65.

19. Rostas JA, Hoffman A, Murtha LA, Pepperall D, McLeod DD, Dickson PW, et al. Ischaemia- and excitotoxicity-induced CaMKII-mediated neuronal cell death: the relative roles of CaMKII autophosphorylation at T286 and T253. Neurochem Int. 2017;104:6-10.

20. Strack S, Barban MA, Wadzinski BE, Colbran RJ. Differential inactivation of postsynaptic density-associated and soluble $\mathrm{Ca} 2+$ /calmodulin-dependent protein kinase II by protein phosphatases 1 and 2A. J Neurochem. 1997;68(5):2119-28.

21. Patton BL, Miller SG, Kennedy MB. Activation of type II calcium/calmodulin-dependent protein kinase by $\mathrm{Ca} 2+/$ calmodulin is inhibited by autophosphorylation of threonine within the calmodulin-binding domain. J Biol Chem. 1990;265(19):1120412.

22. Schworer CM, Colbran RJ, Soderling TR. Reversible generation of a $\mathrm{Ca} 2+$-independent form of $\mathrm{Ca} 2+$ (calmodulin)-dependent protein kinase II by an autophosphorylation mechanism. J Biol Chem. 1986;261(19):8581-4.

23. Lai Y, Nairn AC, Greengard P. Autophosphorylation reversibly regulates the $\mathrm{Ca} 2+/$ calmodulin-dependence of $\mathrm{Ca} 2+/$ calmodulindependent protein kinase II. Proc Natl Acad Sci U S A. 1986;83(12):4253-7.

24. Zalcman G, Federman N, Romano A. CaMKII isoforms in learning and memory: localization and function. Front Mol Neurosci. 2018;11:445.

25. Gray CB, Heller BJ. CaMKIIdelta subtypes: localization and function. Front Pharmacol. 2014;5:15.

26. Bayer KU, Löhler J, Schulman H, Harbers K. Developmental expression of the CaM kinase II isoforms: ubiquitous gammaand delta-CaM kinase II are the early isoforms and most abundant in the developing nervous system. Brain Res Mol Brain Res. 1999;70(1):147-54.

27. Tobimatsu T, Fujisawa H. Tissue-specific expression of four types of rat calmodulin-dependent protein kinase II mRNAs. J Biol Chem. 1989;264(30):17907-12.

28. Ramirez MT, Zhao XL, Schulman H, Brown JH. The nuclear deltaB isoform of $\mathrm{Ca} 2+/$ calmodulin-dependent protein kinase II regulates atrial natriuretic factor gene expression in ventricular myocytes. J Biol Chem. 1997;272(49):31203-8.

29. Zhang T, Kohlhaas M, Backs J, Mishra S, Phillips W, Dybkova N, et al. CaMKIIdelta isoforms differentially affect calcium handling but similarly regulate HDAC/MEF2 transcriptional responses. J Biol Chem. 2007;282(48):35078-87.

30. Ma H, Groth RD, Cohen SM, Emery JF, Li B, Hoedt E, et al. $\gamma$ CaMKII shuttles $\mathrm{Ca}^{2+} / \mathrm{CaM}$ to the nucleus to trigger CREB phosphorylation and gene expression. Cell. 2014;159(2):281-94.

31. Brocke L, Srinivasan M, Schulman H. Developmental and regional expression of multifunctional $\mathrm{Ca} 2+$ /calmodulin-dependent protein kinase isoforms in rat brain. J Neurosci. 1995;15(10):6797808 .

32. Srinivasan M, Edman CF, Schulman H. Alternative splicing introduces a nuclear localization signal that targets multifunctional CaM kinase to the nucleus. J Cell Biol. 1994;126(4):839-52.

33. Heist EK, Srinivasan M, Schulman H. Phosphorylation at the nuclear localization signal of $\mathrm{Ca} 2+$ /calmodulin-dependent protein kinase II blocks its nuclear targeting. J Biol Chem. 1998;273(31): 19763-71.

34. Lin YC, Redmond L. CaMKIIbeta binding to stable F-actin in vivo regulates F-actin filament stability. Proc Natl Acad Sci U S A. 2008;105(41):15791-6.
35. Shen K, Meyer T. Dynamic control of CaMKII translocation and localization in hippocampal neurons by NMDA receptor stimulation. Science. 1999;284(5411):162-6.

36. Ray PD, Huang BW, Tsuji Y. Reactive oxygen species (ROS) homeostasis and redox regulation in cellular signaling. Cell Signal. 2012;24(5):981-90.

37. Anderson ME. Oxidant stress promotes disease by activating CaMKII. J Mol Cell Cardiol. 2015;89(Pt B):160-7.

38. Erickson JR, He BJ, Grumbach IM, Anderson ME. CaMKII in the cardiovascular system: sensing redox states. Physiol Rev. 2011;91(3):889-915.

39. Purohit A, Rokita AG, Guan X, Chen B, Koval OM, Voigt N, et al. Oxidized $\mathrm{Ca}(2+) /$ calmodulin-dependent protein kinase II triggers atrial fibrillation. Circulation. 2013;128(16):1748-57.

40. Bayer KU, De Koninck P, Leonard AS, Hell JW, Schulman H. Interaction with the NMDA receptor locks CaMKII in an active conformation. Nature. 2001;411(6839):801-5.

41. Strack S, McNeill RB, Colbran RJ. Mechanism and regulation of calcium/calmodulin-dependent protein kinase II targeting to the NR2B subunit of the N-methyl-D-aspartate receptor. J Biol Chem. 2000;275(31):23798-806.

42. Alev C, Urschel S, Sonntag S, Zoidl G, Fort AG, Höher T, et al. The neuronal connexin36 interacts with and is phosphorylated by CaMKII in a way similar to CaMKII interaction with glutamate receptors. Proc Natl Acad Sci U S A. 2008;105(52):20964-9.

43. Hudmon A, Schulman H, Kim J, Maltez JM, Tsien RW, Pitt GS. CaMKII tethers to L-type $\mathrm{Ca} 2+$ channels, establishing a local and dedicated integrator of $\mathrm{Ca} 2+$ signals for facilitation. J Cell Biol. 2005;171(3):537-47.

44. Hell JW. CaMKII: claiming center stage in postsynaptic function and organization. Neuron. 2014;81(2):249-65.

45. Vemuganti R. All's well that transcribes well: non-coding RNAs and post-stroke brain damage. Neurochem Int. 2013;63(5):43849.

46. Cha MJ, Jang JK, Ham O, Song BW, Lee SY, Lee CY, et al. MicroRNA-145 suppresses ROS-induced Ca2+ overload of cardiomyocytes by targeting CaMKII $\delta$. Biochem Biophys Res Commun. 2013;435(4):720-6.

47. Xu Q, Deng F, Xing Z, Wu Z, Cen B, Xu S, et al. Long noncoding RNA C2dat1 regulates CaMKIIdelta expression to promote neuronal survival through the NF-kappaB signaling pathway following cerebral ischemia. Cell Death Dis. 2016;7:e2173.

48. Ye J, Das S, Roy A, Wei W, Huang H, Lorenz-Guertin JM, et al. Ischemic injury-induced CaMKIIdelta and CaMKIIgamma confer neuroprotection through the NF-kappaB signaling pathway. Mol Neurobiol. 2019;56(3):2123-36.

49. George PM, Steinberg GK. Novel Stroke Therapeutics: Unraveling stroke pathophysiology and its impact on clinical treatments. Neuron. 2015;87(2):297-309.

50. Ma F, Sun P, Zhang X, Hamblin MH, Yin KJ. Endotheliumtargeted deletion of the miR-15a/16-1 cluster ameliorates bloodbrain barrier dysfunction in ischemic stroke. Sci Signal. 2020;13(626):eaay5686.

51. Sun P, Zhang K, Hassan SH, Zhang X, Tang X, Pu H, et al. Endothelium-targeted deletion of microRNA-15a/16-1 promotes poststroke angiogenesis and improves long-term neurological recovery. Circ Res. 2020;126(8):1040-57.

52. Zhang X, Hamblin MH, Yin KJ. Noncoding RNAs and stroke. Neuroscientist. 2019;25(1):22-6.

53. Ma F, Zhang X, Yin KJ. MicroRNAs in central nervous system diseases: a prospective role in regulating blood-brain barrier integrity. Exp Neurol. 2020;323:113094.

54. Doyle KP, Simon RP, Stenzel-Poore MP. Mechanisms of ischemic brain damage. Neuropharmacology. 2008;55(3):310-8.

55. Moskowitz MA, Lo EH, Iadecola C. The science of stroke: mechanisms in search of treatments. Neuron. 2010;67(2):181-98. 
56. Snider BJ, Gottron FJ, Choi DW. Apoptosis and necrosis in cerebrovascular disease. Ann N Y Acad Sci. 1999;893:243-53.

57. Zalewska T, Bialynicka-Birula K, Domanska-Janik K. Autophosphorylation as a possible mechanism of calcium/ calmodulin-dependent protein kinase II inhibition during ischemia. Neurochem Int. 1996;28(2):175-81.

58. Churn SB, Limbrick D, Sombati S, DeLorenzo RJ. Excitotoxic activation of the NMDA receptor results in inhibition of calcium/ calmodulin kinase II activity in cultured hippocampal neurons. J Neurosci. 1995;15(4):3200-14.

59. Krizbai IA, Deli MA, Pestenacz A, Siklos L, Szabo CA, Andras I, et al. Expression of glutamate receptors on cultured cerebral endothelial cells. J Neurosci Res. 1998;54(6):814-9.

60. Ashpole NM, Hudmon A. Excitotoxic neuroprotection and vulnerability with CaMKII inhibition. Mol Cell Neurosci. 2011;46(4):720-30.

61. Hu BR, Wieloch T. Persistent translocation of Ca2+/calmodulindependent protein kinase II to synaptic junctions in the vulnerable hippocampal CA1 region following transient ischemia. J Neurochem. 1995;64(1):277-84.

62. Hu BR, Kurihara J, Wieloch T. Persistent translocation and inhibition of $\mathrm{Ca} 2+/$ calmodulin-dependent protein kinase II in the crude synaptosomal fraction of the vulnerable hippocampus following hypoglycemia. J Neurochem. 1995;64(3):1361-9.

63. Matsumoto S, Shamloo M, Isshiki A, Wieloch T. Persistent phosphorylation of synaptic proteins following middle cerebral artery occlusion. J Cereb Blood Flow Metab. 2002;22(9):1107-13.

64. Matsumoto S, Shamloo M, Matsumoto E, Isshiki A, Wieloch T. Protein kinase C-gamma and calcium/calmodulin-dependent protein kinase II-alpha are persistently translocated to cell membranes of the rat brain during and after middle cerebral artery occlusion. J Cereb Blood Flow Metab. 2004;24(1):54-61.

65. Bayer KU, LeBel E, McDonald GL, O'Leary H, Schulman H, De Koninck P. Transition from reversible to persistent binding of CaMKII to postsynaptic sites and NR2B. J Neurosci. 2006;26(4):1164-74.

66. Hudmon A, Aronowski J, Kolb SJ, Waxham MN. Inactivation and self-association of $\mathrm{Ca} 2+/$ calmodulin-dependent protein kinase II during autophosphorylation. J Biol Chem. 1996;271(15):88008 .

67. Hudmon A, Lebel E, Roy H, Sik A, Schulman H, Waxham MN, et al. A mechanism for $\mathrm{Ca} 2+/$ calmodulin-dependent protein kinase II clustering at synaptic and nonsynaptic sites based on self-association. J Neurosci. 2005;25(30):6971-83.

68. Vest RS, O'Leary H, Bayer KU. Differential regulation by ATP versus $\mathrm{ADP}$ further links CaMKII aggregation to ischemic conditions. FEBS Lett. 2009;583(22):3577-81.

69. Olmez I, Ozyurt H. Reactive oxygen species and ischemic cerebrovascular disease. Neurochem Int. 2012;60(2):208-12.

70. Erickson JR, Joiner ML, Guan X, Kutschke W, Yang J, Oddis $\mathrm{CV}$, et al. A dynamic pathway for calcium-independent activation of CaMKII by methionine oxidation. Cell. 2008;133(3):462-74.

71. Shetty PK, Huang FL, Huang KP. Ischemia-elicited oxidative modulation of $\mathrm{Ca} 2+/$ calmodulin-dependent protein kinase II. J Biol Chem. 2008;283(9):5389-401.

72. Shackelford DA, Yeh RY, Hsu M, Buzsaki G, Zivin JA. Effect of cerebral ischemia on calcium/calmodulin-dependent protein kinase II activity and phosphorylation. J Cereb Blood Flow Metab. 1995; 15(3):450-61.

73. Zhang X, Tang X, Ma F, Fan Y, Sun P, Zhu T, et al. Endotheliumtargeted overexpression of Kruppel-like factor 11 protects the blood-brain barrier function after ischemic brain injury. Brain Pathol. 2020;30:746-65.

74. Zhang X, Tang X, Liu K, Hamblin MH, Yin KJ. Long noncoding RNA Malat1 regulates cerebrovascular pathologies in ischemic stroke. J Neurosci. 2017;37(7):1797-806.
75. Ashpole NM, Song W, Brustovetsky T, Engleman EA, Brustovetsky N, Cummins TR, et al. Calcium/calmodulindependent protein kinase II (CaMKII) inhibition induces neurotoxicity via dysregulation of glutamate/calcium signaling and hyperexcitability. J Biol Chem. 2012;287(11):8495-506.

76. Liu Z, Xu J, Shen X, Lv C, Xu T, Pei D. CaMKII antisense oligodeoxynucleotides protect against ischemia-induced neuronal death in the rat hippocampus. J Neurol Sci. 2012;314(1-2):104 10 .

77. Waldsee R, Eftekhari S, Ahnstedt H, Johnson LE, Edvinsson L. CaMKII and MEK1/2 inhibition time-dependently modify inflammatory signaling in rat cerebral arteries during organ culture. $\mathrm{J}$ Neuroinflammation. 2014;11:90.

78. Liu Z, Huang Y, Liu L, Zhang L. Inhibitions of PKC and CaMK-II synergistically rescue ischemia-induced astrocytic dysfunction. Neurosci Lett. 2017;657:199-203.

79. Li J, Zhang S, Liu X, Han D, Xu J, Ma Y. Neuroprotective effects of leonurine against oxygen-glucose deprivation by targeting Cx36/CaMKII in PC12 cells. PLoS One. 2018;13(7):e0200705.

80. Wei Y, Wang R, Teng J. Inhibition of calcium/calmodulindependent protein kinase IIalpha suppresses oxidative stress in cerebral ischemic rats through targeting glucose 6-phosphate dehydrogenase. Neurochem Res. 2019;44(7):1613-20.

81. Qu Y, Tang J, Wang H, Li S, Zhao F, Zhang L, et al. RIPK3 interactions with MLKL and CaMKII mediate oligodendrocytes death in the developing brain. Cell Death Dis. 2017;8(2):e2629.

82. Chalmers NE, Yonchek J, Steklac KE, Ramsey M, Bayer KU, Herson PS, et al. Calcium/calmodulin-dependent kinase (CaMKII) inhibition protects against Purkinje cell damage following CA/CPR in mice. Mol Neurobiol. 2020;57(1):150-8.

83. Waxham MN, Grotta JC, Silva AJ, Strong R, Aronowski J. Ischemia-induced neuronal damage: a role for calcium/ calmodulin-dependent protein kinase II. J Cereb Blood Flow Metab. 1996;16(1):1-6.

84. Ashpole NM, Chawla AR, Martin MP, Brustovetsky T, Brustovetsky N, Hudmon A. Loss of calcium/calmodulindependent protein kinase II activity in cortical astrocytes decreases glutamate uptake and induces neurotoxic release of ATP. J Biol Chem. 2013;288(20):14599-611.

85. Choi DW. Excitotoxic cell death. J Neurobiol. 1992;23(9):126176.

86. Lau A, Tymianski M. Glutamate receptors, neurotoxicity and neurodegeneration. Pflugers Arch. 2010;460(2):525-42.

87. Berliocchi L, Bano D, Nicotera P. Ca2+ signals and death programmes in neurons. Philos Trans R Soc Lond B Biol Sci. 2005;360(1464):2255-8.

88. Clapham DE. Calcium signaling. Cell. 2007;131(6):1047-58.

89. Cao X, Zhang Y, Zou L, Xiao H, Chu Y, Chu X. Persistent oxygen-glucose deprivation induces astrocytic death through two different pathways and calpain-mediated proteolysis of cytoskeletal proteins during astrocytic oncosis. Neurosci Lett. 2010;479(2):118-22.

90. Chu X, Fu X, Zou L, Qi C, Li Z, Rao Y, et al. Oncosis, the possible cell death pathway in astrocytes after focal cerebral ischemia. Brain Res. 2007;1149:157-64.

91. Fricker M, Tolkovsky AM, Borutaite V, Coleman M, Brown GC. Neuronal cell death. Physiol Rev. 2018;98(2):813-80.

92. Liu C, Zhang K, Shen H, Yao X, Sun Q, Chen G. Necroptosis: a novel manner of cell death, associated with stroke (Review). Int J Mol Med. 2018;41(2):624-30.

93. Hribljan V, Lisjak D, Petrovic DJ, Mitrecic D. Necroptosis is one of the modalities of cell death accompanying ischemic brain stroke: from pathogenesis to therapeutic possibilities. Croat Med J. 2019;60(2):121-6. 
94. Galluzzi L, Kepp O, Krautwald S, Kroemer G, Linkermann A. Molecular mechanisms of regulated necrosis. Semin Cell Dev Biol. 2014;35:24-32.

95. Ling WY, Cui Y, Gao JL, Jiang XH, Wang KJ, Tian YX, et al. Long-term chemogenetic activation of M1 glutamatergic neurons attenuates the behavioral and cognitive deficits caused by intracerebral hemorrhage. Biochem Biophys Res Commun. 2020;527(1): $22-8$.

96. Zhan L, Lu Z, Zhu X, Xu W, Li L, Li X, et al. Hypoxic preconditioning attenuates necroptotic neuronal death induced by global cerebral ischemia via Drp1-dependent signaling pathway mediated by CaMKIIalpha inactivation in adult rats. FASEB J. 2019;33(1):1313-29.

97. Broughton BR, Reutens DC, Sobey CG. Apoptotic mechanisms after cerebral ischemia. Stroke. 2009;40(5):e331-9.

98. Woodruff TM, Thundyil J, Tang SC, Sobey CG, Taylor SM, Arumugam TV. Pathophysiology, treatment, and animal and cellular models of human ischemic stroke. Mol Neurodegener. 2011;6(1):11

99. Uzdensky AB. Apoptosis regulation in the penumbra after ischemic stroke: expression of pro- and antiapoptotic proteins. Apoptosis. 2019;24(9-10):687-702.

100. Takano H, Fukushi H, Morishima Y, Shirasaki Y. Calmodulin and calmodulin-dependent kinase II mediate neuronal cell death induced by depolarization. Brain Res. 2003;962(1-2):41-7.

101. Gao J, Duan B, Wang DG, Deng XH, Zhang GY, Xu L, et al. Coupling between NMDA receptor and acid-sensing ion channel contributes to ischemic neuronal death. Neuron. 2005;48(4):63546.

102. Ahmed ME, Dong Y, Lu Y, Tucker D, Wang R, Zhang Q. Beneficial effects of a CaMKIIalpha inhibitor TatCN21 peptide in global cerebral ischemia. J Mol Neurosci. 2017;61(1):42-51.

103. Butler LS, Silva AJ, Abeliovich A, Watanabe Y, Tonegawa S, McNamara JO. Limbic epilepsy in transgenic mice carrying a $\mathrm{Ca} 2+/$ calmodulin-dependent kinase II alpha-subunit mutation. Proc Natl Acad Sci U S A. 1995;92(15):6852-5.

104. Koike M, Shibata M, Tadakoshi M, Gotoh K, Komatsu M, Waguri S, et al. Inhibition of autophagy prevents hippocampal pyramidal neuron death after hypoxic-ischemic injury. Am J Pathol. 2008;172(2):454-69.

105. Gabryel B, Kost A, Kasprowska D. Neuronal autophagy in cerebral ischemia-a potential target for neuroprotective strategies? Pharmacol Rep. 2012;64(1):1-15.

106. Wang P, Shao BZ, Deng Z, Chen S, Yue Z, Miao CY. Autophagy in ischemic stroke. Prog Neurobiol. 2018:163-164:98-117.

107. Li X, Wu XQ, Deng R, Li DD, Tang J, Chen WD, et al. CaMKIImediated Beclin 1 phosphorylation regulates autophagy that promotes degradation of Id and neuroblastoma cell differentiation. Nat Commun. 2017;8(1):1159.

108. Kong L, Xiong F, Sun N, Xu C, Chen Y, Yang J, et al. CaMKIIdelta inhibition protects against myocardial ischemia/ reperfusion injury: Role of Beclin-1-dependent autophagy. Eur J Pharmacol. 2020;886:173539.

109. Vest RS, O'Leary H, Coultrap SJ, Kindy MS, Bayer KU. Effective post-insult neuroprotection by a novel $\mathrm{Ca}(2+) /$ calmodulin-dependent protein kinase II (CaMKII) inhibitor. J Biol Chem. 2010;285(27):20675-82.

110. Kulbe JR, Mulcahy Levy JM, Coultrap SJ, Thorburn A, Bayer $\mathrm{KU}$. Excitotoxic glutamate insults block autophagic flux in hippocampal neurons. Brain Res. 2014;1542:12-9.

111. Ruetzler CA, Furuya K, Takeda H, Hallenbeck JM. Brain vessels normally undergo cyclic activation and inactivation: evidence from tumor necrosis factor-alpha, heme oxygenase-1, and manganese superoxide dismutase immunostaining of vessels and perivascular brain cells. J Cereb Blood Flow Metab. 2001;21(3): 244-52.
112. Huang J, Upadhyay UM, Tamargo RJ. Inflammation in stroke and focal cerebral ischemia. Surg Neurol. 2006;66(3):232-45.

113. Bohm F, Pernow J. The importance of endothelin-1 for vascular dysfunction in cardiovascular disease. Cardiovasc Res. 2007:76(1):8-18.

114. Lin CC, Hsieh HL, Chi PL, Yang CC, Hsiao LD, Yang CM. Upregulation of COX-2/PGE2 by ET-1 mediated through Ca2+dependent signals in mouse brain microvascular endothelial cells. Mol Neurobiol. 2014;49(3):1256-69.

115. Kirsch $\mathrm{M}$, De Groot $\mathrm{H}$. NAD $(\mathrm{P}) \mathrm{H}$, a directly operating antioxidant? FASEB J. 2001;15(9):1569-74.

116. Deli MA, Joo F, Krizbai I, Lengyel I, Nunzi MG, Wolff JR. Calcium/calmodulin-stimulated protein kinase II is present in primary cultures of cerebral endothelial cells. J Neurochem. 1993;60(5):1960-3.

117. Enslen H, Sun P, Brickey D, Soderling SH, Klamo E, Soderling TR. Characterization of $\mathrm{Ca} 2+/$ calmodulin-dependent protein kinase IV. Role in transcriptional regulation. J Biol Chem. 1994;269(22):15520-7.

118. Chang BH, Mukherji S, Soderling TR. Characterization of a calmodulin kinase II inhibitor protein in brain. Proc Natl Acad Sci U S A. 1998;95(18):10890-5.

119. Schwartz JJ, Zhang S. Peptide-mediated cellular delivery. Curr Opin Mol Ther. 2000;2(2):162-7.

120. Abraham MK, Chang WW. Subarachnoid hemorrhage. Emerg Med Clin North Am. 2016;34(4):901-16.

121. Kolias AG, Sen J, Belli A. Pathogenesis of cerebral vasospasm following aneurysmal subarachnoid hemorrhage: putative mechanisms and novel approaches. J Neurosci Res. 2009;87(1):1-11.

122. Vergouwen MD, Ilodigwe D, Macdonald RL. Cerebral infarction after subarachnoid hemorrhage contributes to poor outcome by vasospasm-dependent and -independent effects. Stroke. 2011;42(4):924-9.

123. Al-Khindi T, Macdonald RL, Schweizer TA. Cognitive and functional outcome after aneurysmal subarachnoid hemorrhage. Stroke. 2010;41(8):e519-36.

124. Bederson JB, Levy AL, Ding WH, Kahn R, DiPerna CA, Jenkins AL 3rd, et al. Acute vasoconstriction after subarachnoid hemorrhage. Neurosurgery. 1998;42(2):352-60 discussion 60-2.

125. Bederson JB, Connolly ES Jr, Batjer HH, Dacey RG, Dion JE, Diringer MN, et al. Guidelines for the management of aneurysmal subarachnoid hemorrhage: a statement for healthcare professionals from a special writing group of the Stroke Council, American Heart Association. Stroke. 2009;40(3):994-1025.

126. Parker BL, Larsen MR, Edvinsson LI, Povlsen GK. Signal transduction in cerebral arteries after subarachnoid hemorrhage-a phosphoproteomic approach. J Cereb Blood Flow Metab. 2013;33(8):1259-69.

127. Edvinsson L, Povlsen GK, Ahnstedt H, Waldsee R. CaMKII inhibition with KN93 attenuates endothelin and serotonin receptormediated vasoconstriction and prevents subarachnoid hemorrhage-induced deficits in sensorimotor function. J Neuroinflammation. 2014;11:207.

128. Zhou K, Enkhjargal B, Xie Z, Sun C, Wu L, Malaguit J, et al. Dihydrolipoic acid inhibits lysosomal rupture and NLRP3 through lysosome-associated membrane protein-1/calcium/calmodulin-dependent protein kinase II/TAK1 pathways after subarachnoid hemorrhage in Rat. Stroke. 2018;49(1):175-83.

129. Han SM, Wan H, Kudo G, Foltz WD, Vines DC, Green DE, et al. Molecular alterations in the hippocampus after experimental subarachnoid hemorrhage. J Cereb Blood Flow Metab. 2014;34(1): 108-17.

130. Esiri MM, Wilcock GK, Morris JH. Neuropathological assessment of the lesions of significance in vascular dementia. $\mathrm{J}$ Neurol Neurosurg Psychiatry. 1997;63(6):749-53. 
131. O'Brien JT, Erkinjuntti T, Reisberg B, Roman G, Sawada T, Pantoni L, et al. Vascular cognitive impairment. Lancet Neurol. 2003;2(2):89-98.

132. Fukunaga K, Stoppini L, Miyamoto E, Muller D. Long-term potentiation is associated with an increased activity of $\mathrm{Ca} 2+/$ calmodulin-dependent protein kinase II. J Biol Chem. 1993;268(11): 7863-7.

133. Yamamoto Y, Shioda N, Han F, Moriguchi S, Nakajima A, Yokosuka A, et al. Nobiletin improves brain ischemia-induced learning and memory deficits through stimulation of CaMKII and CREB phosphorylation. Brain Res. 2009;1295:218-29.

134. Wang XJ, Gao YP, Lu NN, Li WS, Xu JF, Ying XY, et al. Endogenous polysialic acid based micelles for calmodulin antagonist delivery against vascular dementia. ACS Appl Mater Interfaces. 2016;8(51):35045-58.

135. Wang R, Yin YX, Mahmood Q, Wang XJ, Gao YP, Gou GJ, et al. Calmodulin inhibitor ameliorates cognitive dysfunction via inhibiting nitrosative stress and NLRP3 signaling in mice with bilateral carotid artery stenosis. CNS Neurosci Ther. 2017;23(10):818-26.

136. Li W, Yuan H, Yu Y, Cheong YK, Ren G, Yang Z. Etidronate rescues cognitive deficits through improving synaptic transmission and suppressing apoptosis in 2-vessel occlusion model rats. J Neurochem. 2017;140(3):476-84.

137. Yang J, Yao Y, Wang L, Yang C, Wang F, Guo J, et al. Gastrinreleasing peptide facilitates glutamatergic transmission in the hippocampus and effectively prevents vascular dementia induced cognitive and synaptic plasticity deficits. Exp Neurol. 2017;287(Pt 1):75-83.

138. Zhao Q, Yokozawa T, Yamabe N, Tsuneyama K, Li X, Matsumoto K. Kangen-karyu improves memory deficit caused by aging through normalization of neuro-plasticity-related signaling system and VEGF system in the brain. J Ethnopharmacol. 2010;131(2):377-85.

139. Armbrecht HJ, Boltz MA, Kumar VB, Flood JF, Morley JE. Effect of age on calcium-dependent proteins in hippocampus of senescence-accelerated mice. Brain Res. 1999;842(2):287-93.

140. Abbott NJ, Ronnback L, Hansson E. Astrocyte-endothelial interactions at the blood-brain barrier. Nat Rev Neurosci. 2006;7(1): 41-53.

141. Begley DJ, Brightman MW. Structural and functional aspects of the blood-brain barrier. Prog Drug Res. 2003;61:39-78.

142. Leak RK, Zhang L, Stetler RA, Weng Z, Li P, Atkins GB, et al. HSP27 protects the blood-brain barrier against ischemia-induced loss of integrity. CNS Neurol Disord Drug Targets. 2013;12(3): 325-37.

143. Krupinski J, Kaluza J, Kumar P, Kumar S, Wang JM. Role of angiogenesis in patients with cerebral ischemic stroke. Stroke. 1994;25(9):1794-8.

Publisher's Note Springer Nature remains neutral with regard to jurisdictional claims in published maps and institutional affiliations. 